\title{
Experimental and Numerical Analysis of Rheological Properties of Invert Emulsion Mud and Its Use for Pressure Control
}

\author{
dominic Onimowo ${ }^{1}$ \\ ${ }^{1}$ Colchester Institute
}

May 5, 2020

\begin{abstract}
Emulsion muds are water based drilling fluids, which contain dispersed oil or synthetic hydrocarbon as an internal phase. Drilling muds are very multifaceted liquids mostly made of up clay suspensions and other materials used as circulatory fluids during well drilling. The ability of drilling fluids, in particular invert emulsion muds to perform their functions, such as removal and transportation of cuttings from the well, lubrication and cooling of drill bits and parts, well wall support and formation fluid containment is all dependent on the rheological properties such as their elasticity, plasticity, viscosity and how they flow and distort. The objective of this paper is to carry out an experimental study on oil based drilling fluid; invert emulsion mud, study its rheological properties, its formulation and how they affect well construction and stability. The mud mixture would also be simulated using Drill Bench.
\end{abstract}

\section{Experimental and Numerical Analysis of Rheological Properties of Invert Emulsion Mud and Its Use for Pressure Control}

Onimowo, Dominic A.

\begin{abstract}
Emulsion muds are water based drilling fluids, which contain dispersed oil or synthetic hydrocarbon as an internal phase. Drilling muds are very multifaceted liquids mostly made of up clay suspensions and other materials used as circulatory fluids during well drilling. The ability of drilling fluids, in particular invert emulsion muds to perform their functions, such as removal and transportation of cuttings from the well, lubrication and cooling of drill bits and parts, well wall support and formation fluid containment is all dependent on the rheological properties such as their elasticity, plasticity, viscosity and how they flow and distort. The objective of this paper is to carry out an experimental study on oil based drilling fluid; invert emulsion mud, study its rheological properties, its formulation and how they affect well construction and stability. The mud mixture would also be simulated using Drill Bench.
\end{abstract}

Index Terms: Drill bench, Invert emulsion mud, pressure control, Rheology, Drilling fluids, Kick, oil recovery

\subsection{INTRODUCTION}

A typical drilling fluid mixture is constituent of various additives each of which plays their specific role in the drilling fluid. Drilling fluid rheology, which is practically the most important of these characteristics, is highly dependent on the constituents of the mixture. The rheology must be accurate in order to achieve 
basic goals such as cuttings removal, well stability and cleaning operations. Drilling mud rheology is highly affected by temperature, pressure and aging [1] and additives such as Versaclean and $\mathrm{pH}$ modifiers in this case. Standard rheological models such as the Bingham model (1925), the power law model (1925) and the Herschel Bulkley model (1926) are used in order to gain full knowledge of drilling fluid rheology. The drilling fluid being considered in this paper is a type of oil-based mud, Invert emulsion mud and in order to understand and fully analyse its rheology, research for this paper will correlate data collected from an experiment carried out, a drill bench simulation and the standard rheological models. The rheology and properties of drilling mud, its formulation and how they affect well construction and stability will then be noted.

\subsection{Oil Based Drilling Mud System Rheology}

The design of an effective drilling mud rheology system means that the drilling mud has been conditioned to act properly despite terrible circumstances such as a modification in the rheological formation of the mud, extreme temperatures and pressures. The paper aims at studying the rheological properties of oil based drilling fluids using a lab mad model and a drill bench simulation after which its use in pressure control and well stability maintenance would be analysed. In order to achieve this, a drilling mud sample was developed from scratch to be used in the experiment. The characterization of rheological properties was started since schwedoff in 1890 who worked on colloidal gelatin solutions from which he discovered that the torque experience in a drilling mud system was not proportional to the angular velocity. This contradicted newton's theory hence it was concluded that drilling muds were non-Newtonian fluids. Trouton used the yield stress value in 1904 to achieve a value that matched the flow rate proportionally while in the years 1922, 1925 and 1926; Bingham, Ostwald, Herschel and Bulkley respectively continued to develop on the notion from schwedoff about the non-Newtonian nature of drilling muds. The use of factors such as gel strength, yield stress, viscosity, and shear stress which can only be obtained from drilling mud experiments are used to develop models which are compared to the previously listed rheological models and this is necessary for the successful characterization and study of the rheological properties of emulsion muds and their use for pressure control.

\subsubsection{Plastic Viscosity (Centi Poise (CP))}

The gradient of the slope of a shear stress versus shear rate curve, which are parameters of the Bingham plastic model above the yield point is known as the plastic viscosity. This is also represented when the viscosity curve of a sample of drilling mud is extrapolated to infinite shear rate on the foundation of the arithmetic of the Bingham model [3]. In the field and in this paper, it is measured using a viscometer, which basically measured various shear rates at $600 \mathrm{rpm}, 300 \mathrm{rpm}, 200 \mathrm{rpm}, 100 \mathrm{rpm}, 6 \mathrm{rpm}$ and $3 \mathrm{rpm}$. After the various shear rates have been measured, it is possible to calculate the plastic viscosity by subtracting the $300 \mathrm{rpm}$ shear rate from the $600 \mathrm{rpm}$ shear rate. The equation for this is as shown below.

Plastic Viscosity (PV)

= Reading at $600 \mathrm{rpm}-$ Reading at $300 \mathrm{rpm}$ (1)

A drilling mud system that permits rapid drilling due to the low viscosity of the mud exiting at the bit is said to have a low plastic viscosity while a presence of colloidal solids and viscous base fluids can lead to a high plastic viscosity drilling mud system. Reduction of the plastic viscosity value can be achieved by diluting the drilling mud system.

\subsubsection{Yield Point (Lb/100ft2)}

The yield stress extrapolated to a shear rate of zero is known as yield point. It is also an important parameter of the Bingham plastic model, which is used to evaluate the ability of a mud to lift cuttings and debris out of the annulus. On a Bingham plastic fluid plot of shear rate versus shear stress, the yield point is the zero shear rate intercept. The yield point is calculated using the $300 \mathrm{rpm}$ shear rate reading and the $600 \mathrm{rpm}$ 
shear rate reading from the viscometer [3]. A non-Newtonian fluid such as a drilling mud system which has a high yield point would transport drill cuttings better than another fluid of a lower yield point but a similar density. In order to lower the yield point, deflocculants are added to clay based mud drilling systems while to increase it, freshly dispersed flocculants such as lime are added to the drilling mud system. The equation used to calculate the yield point is as shown below.

Yield Point (YP)

$=$ Reading at 300 rpm - Plastic Viscosity $(\mathrm{PV})(2)$

\subsubsection{Gel Strength}

The value derived when the shear stress of a drilling mud system is measured after being allowed to set inertly for a period of time usually 10 seconds or 10 minutes according to the American Petroleum Institute (API) standard at a very low shear rate is known as the gel strength it is an important property of a drilling fluid system because it dictates its capacity of the mud to suspend drill cuttings and weighting materials when circulation is stopped. The types of gel strength experienced by a drilling fluids system are shown below [3].

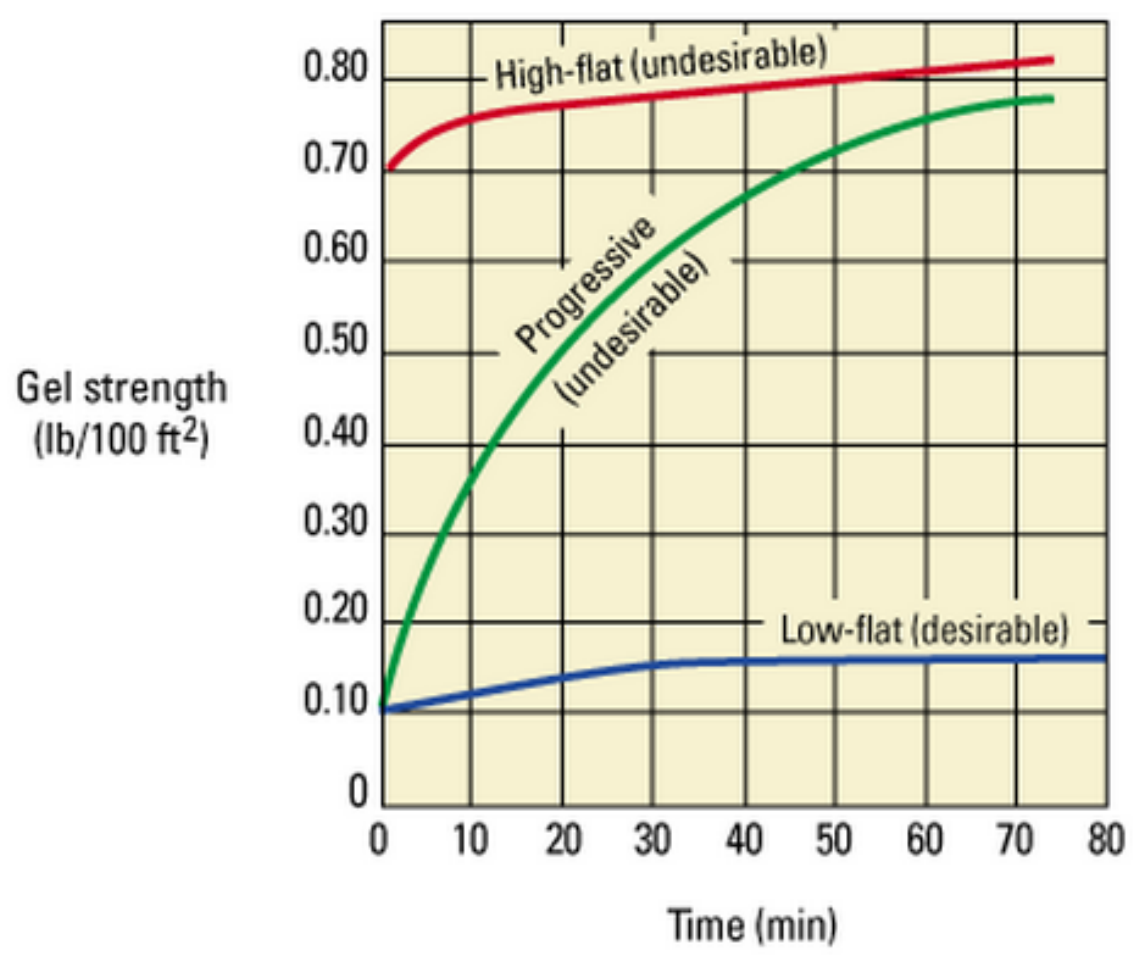

Figure 1: types of gel strengths in muds (source: Oilfield Glossary, 2014)

The gel strength is calculated using the 3-rpm reading, which is recorded after the mud sample, has been stirred at $600 \mathrm{rpm}$ using a viscometer. The first reading is usually a 10 second reading while the second is usually 10 minutes. If a third reading is to be taken, it would usually be measured at 30 minutes and this is because this reading will inform us about the amount of gel the mud sample would experience when exposed to excessive static periods [2]. A drilling mud circulation system with high gel strength will require a high pump pressure to break circulation when the mud has been inert for a long time. Some of the factors that 
contribute to a high gel strength value in a drilling mud system are over treatment with carbon-based gelling substances and a build-up of fine particles of solids in the mud

\subsection{Pseudo plastic and Dilatant Physiognomies}

Pseudo plasticity is a phenomenon displayed by drilling mud systems where the viscosity of the fluid decreases with an increase in shear rate. This is also known as shear thinning. The reverse case of the viscosity of the fluid increasing with an increase in the shear rate is termed dilatant also known as shear thickening. It is affected by properties such as particle size, shape and dissemination all of which are controlled by the Hamaker theory and Van der Waals forces.

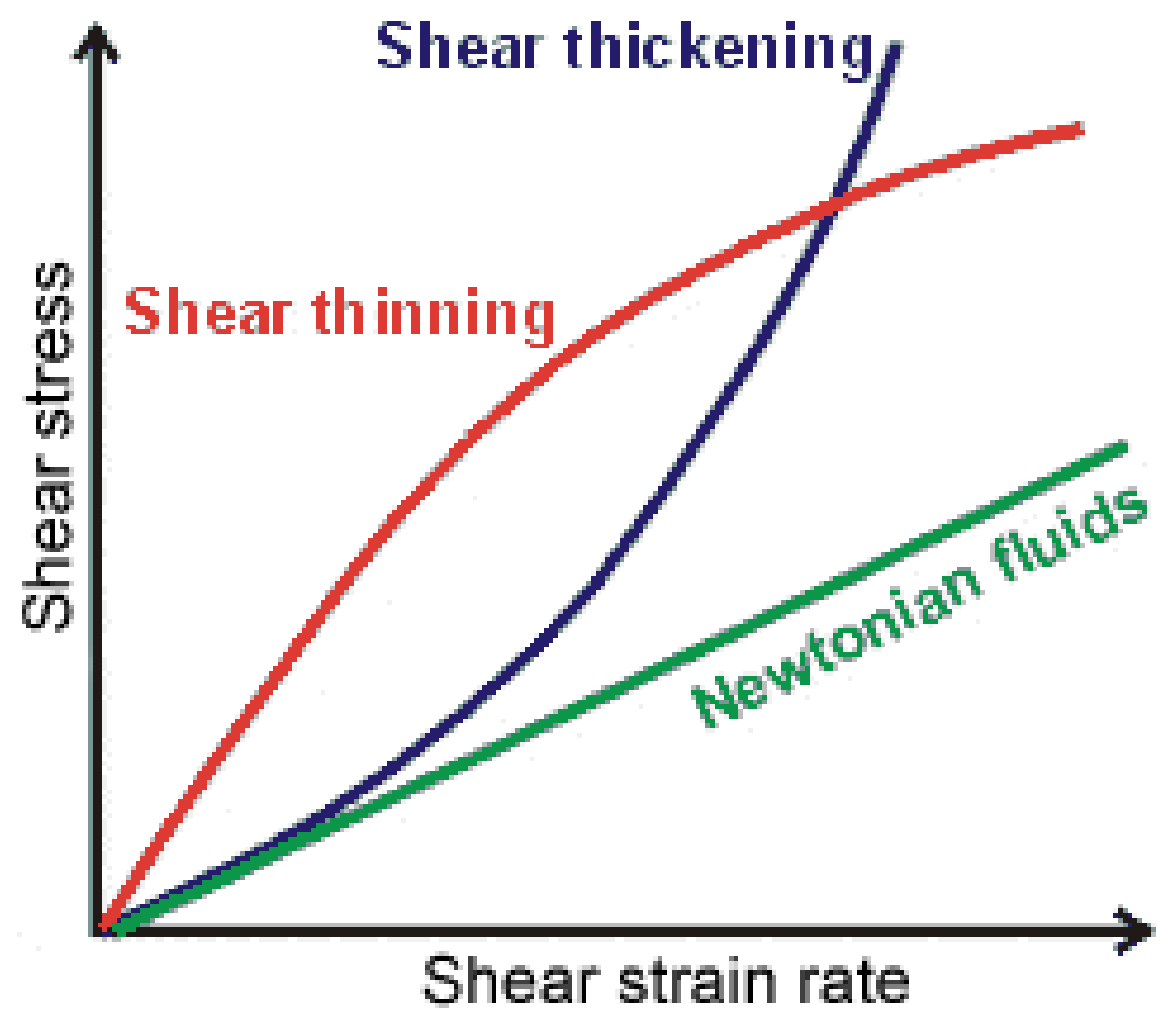

Figure 2: Pseudo plastic and Dilatant characteristics (Source: Chaplin, 2014)

\subsection{Rheological Models of Oil Based Mud Drilling Systems}

Rheological models are basically graphical forms of arithmetic facsimiles used to describe the flow pattern of a drilling fluid system sample. There are three very popular rheological models that are known in the oil and gas industry. These are the Bingham plastic model, he Power law model also known as the Ostwald de Weale model and the Herschel Bulkley model [6].

\subsubsection{Bingham Plastic model}

The Bingham Plastic model is a two parameter rheological model, which was presented by Eugene C. Bingham in 1922. The model is used in the oil and gas industry to portray the various flow physiognomies exhibited by different drilling mud systems. The fluids and drilling mud systems, which obey this law display, a liner shear stress versus shear rate curve after an initial shear stress brink has been reached and they are classified as Bingham Plastic fluids [3]. A desired drilling fluid should have an as low as possible plastic viscosity, achieved by minimizing the influx of colloidal solids to allow for rapid drilling while on the other hand, the yield point must be high enough but not excessive as this can lead to excessive pump pressure 
being needed to break the gel, to transport cuttings and debris out of the hole. Authors such as Herrick (1932), Babson and jones (1935) and Fitzpatrick (1955) all preferred the Bingham Plastic model to describe drilling mud systems. The Bingham Plastic model can be written arithmetically as shown below.

$\tau=Y P+P V(\gamma)(3)$

where, $\tau$ : measures shear stess in $\quad l b / 100 \mathrm{ft}^{2}, Y P$ : Yield Point, PV : Plastic Viscosity , $\gamma$ : measures shear rate in $\quad \mathrm{sec}^{-1}$

\section{Bingham Plastic Model}

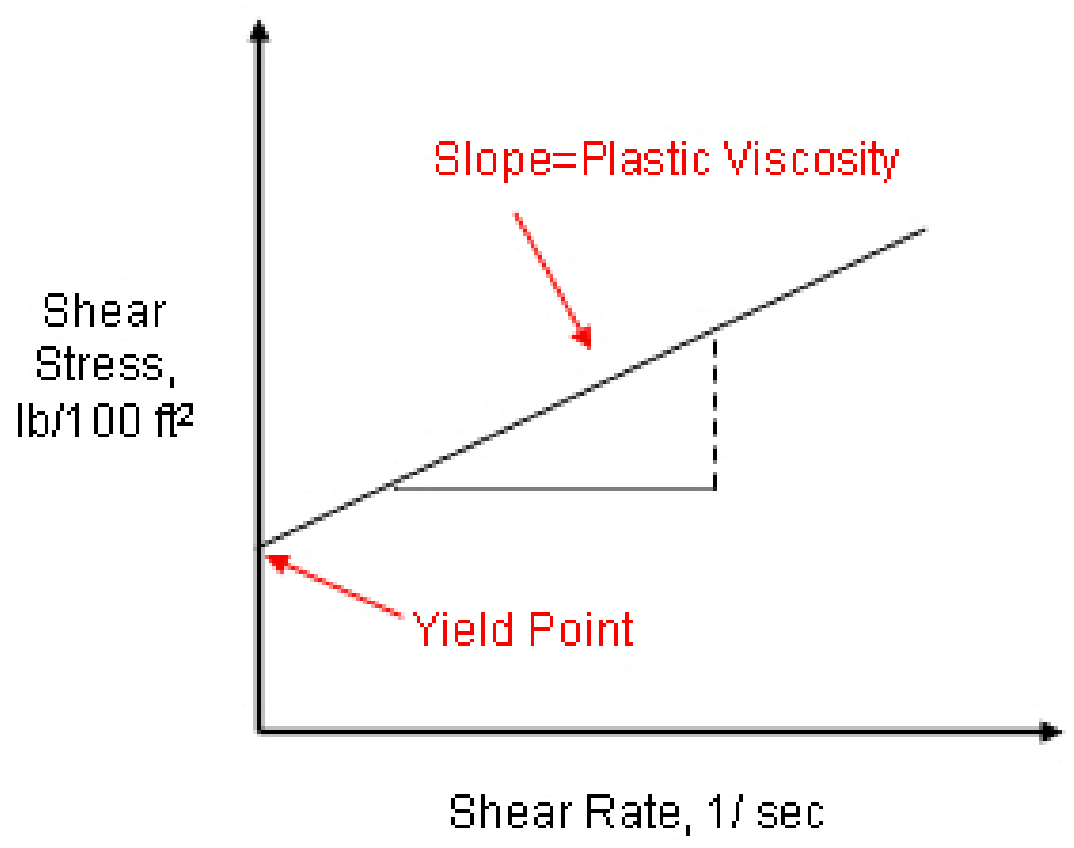

Figure 3: Bingham Plastic Model (Source: Drilling mud, 2014)

\subsubsection{Power Law Model}

According to the [3], a fluid that obeys the Power Law model is one which can be characterized using the two parameter rheological model of a pseudo plastic or shear thinning fluid. A shear thinning fluid is one in which the viscosity of the fluid decreases as its shear rate increases. The power law model can be described arithmetically as shown below.

$\tau=(\gamma)^{n}$

where, $\tau=$ shear stress, $\gamma=$ shear rate, $n=$ exponent and $=$ consstency

However, Herschel and Bulkley developed another model based on the power law model and this was known as the Yield power law model [5]. The yield power law model merges the theoretical aspects of the Bingham plastic model and the practical aspects of the power law model. 


\section{Power Law Model}

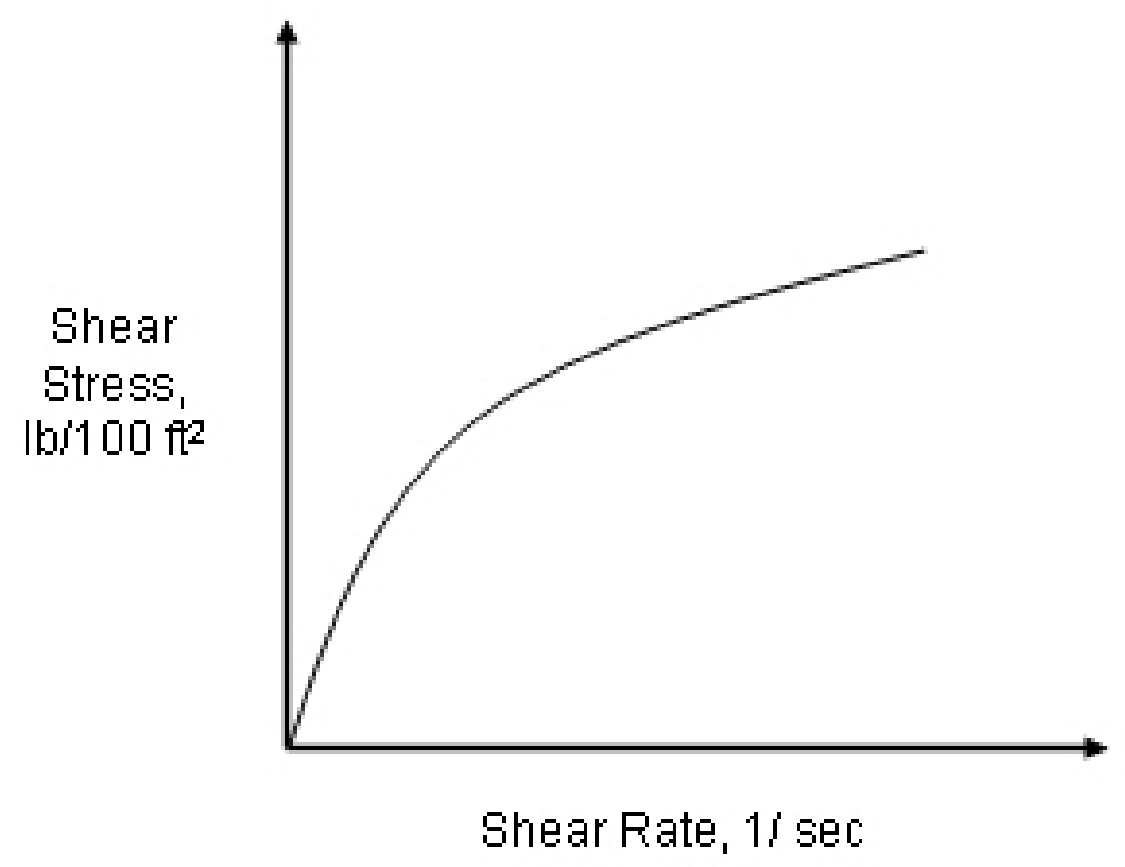

Figure 4: Power law Model (Source: Drilling mud, 2014)

\subsubsection{Herschel Bulkley Model}

The Herschel Bulkley model was introduced in 1926. Unlike the Bingham plastic model and the Power law model, which are both two parameter rheological models, the Herschel and Bulkley model is a three parameter rheological model. The Herschel-Bulkley equation is preferred to power law or Bingham relationships because it results in more accurate models of rheological behaviour when adequate experimental data are available. The graphical model derived from the arithmetic interpretation is called the Herschel-Bulkley model or the yield power law model as stated by [4]. The arithmetic equation of the Herschel Bulkley model is shown below.

$\tau=\tau_{0}+\mu x(\gamma)^{n}$

$$
\begin{aligned}
& \text { where, } \tau \\
& =\text { shear stress of the fluid measured in } \frac{\mathrm{lb}}{100 \mathrm{ft}^{2}} \\
& \tau_{0}=\text { yield stress of the fluid measured in } \frac{\mathrm{lb}}{100 \mathrm{ft}^{2}} \\
& n=\text { power law exponent and flow index of the fluid }
\end{aligned}
$$




$$
\gamma=\text { fluid shear rate measured in } \mathrm{sec}^{-1}
$$

$\mu=$ Consistency index of the fluid measured in $\mathrm{CP}$

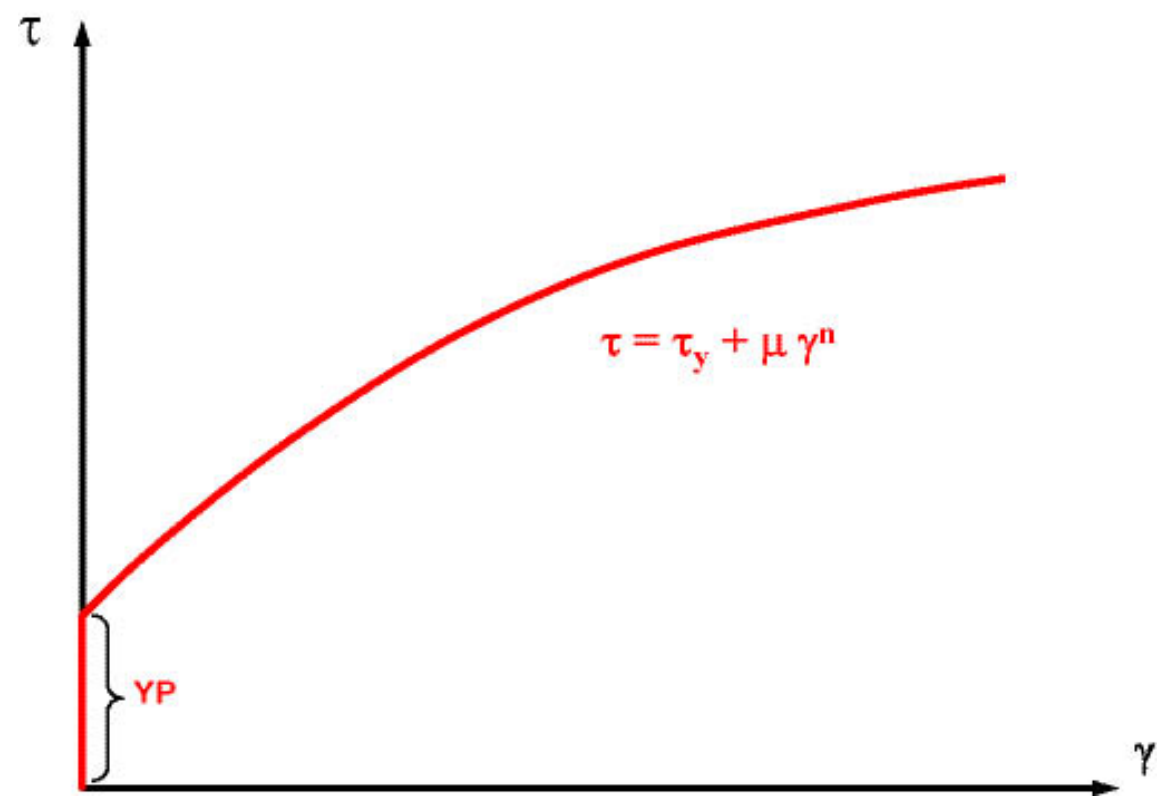

Figure 5: Herschel and Bulkley model at zero shear rate (source: Drilling Contractor, 2009)

\subsection{Methodology}

The following steps had to be taken and in some cases repeated in order to achieve the target results.

Table 1: Sample formulation methodology

\begin{tabular}{lll}
\hline No. & Step & Description \\
\hline 1 & Preparation & Mixing of the base oil and water \\
2 & Weighting & Testing the initial weight to see if appropriate \\
3 & Mud preparation & Addition of weighting agent \\
4 & Mud weighting & Measure the weight of the mud to see if it meets the required standard \\
5 & pH test & Testing for alkalinity or acidity \\
6 & Addition of additives & Addition of phosphoric acid or caustic acid dependent on the result of the pH test \\
7 & Viscometer test & This is to find out the mud rheology, viscosity, yield point and gel strength \\
8 & Marsh funnel test & To find out its flow time and water loss \\
\hline
\end{tabular}

\section{Formulation of the Mud Sample}

The formulation of the mud sample was the first step carried out in the course of the experiment. The apparatus used were the Hamilton Beach mixer, stopwatch, thermometer, mud cup and mud balance. The oil based mud sample was prepared by mixing all the required constituents in a particular order using the Hamilton beach mixer for about two minutes. The formulation procedure is as described, The required amount base oil (Jatropha oil), $280 \mathrm{ml}$ and distilled water $(70 \mathrm{ml}$ ) are added to the mixing container in an 80 to 20 ratio respectively, 22.5 grams of bentonite is added to the mixing container and stirred for two minutes, 
$4 \mathrm{ml}$ of Versaclean VB, the emulsifying agent is added and the mixture is stirred again for two minutes, The $\mathrm{pH}$ was noted, 6 droplets of caustic were added to reduce the $\mathrm{pH}$, The mixture was further stirred for 15 minutes, The $\mathrm{pH}$ was taken again, Final mud sample was transferred to a cup, sealed and left to age for approximately 16 hours. The table below outlines the components required to formulate the mud used for the experiment.

Table 2: Requirements for mud sample

\begin{tabular}{llll}
\hline No & Component & Purpose & Amount \\
\hline 1 & Jatropha oil (base oil) & Thinner (continuous phase) & $280 \mathrm{ml}$ \\
2 & Distilled water & Solute & $70 \mathrm{ml}$ \\
3 & Bentonite & Weighting agent & $22.5 \mathrm{~g}$ \\
4 & Caustic acid & pH adjustment (increase) & Droplets dependent on requirement \\
5 & Versaclean VB & Emulsifying agent & $4 \mathrm{ml}$ \\
6 & Phosphoric acid & $\mathrm{pH}$ adjustment (reduction) & Droplets dependent on requirement \\
\hline
\end{tabular}

\subsection{Experimental Phase}

Table 3: requirements for experimental phase

\begin{tabular}{ll}
\hline Requirement & Depiction \\
\hline Oil to Water ratio & $80 / 20$ \\
Yield stress & Ranges between 14 to $25 \mathrm{lb} . / \mathrm{ft}^{2}$ \\
Gel strength & Changes with time \\
Density & Ranges between 12 and $14 \mathrm{ppg}$ \\
Filtrate loss & Less than $4 \mathrm{ml}$ \\
\hline
\end{tabular}

For numerical simulation, the software package, Drill Bench was used to develop a well trajectory and model with the data given.

\subsection{Results and Discussion}

The preparation of the mud sample to be used for the experiment is represented by the arithmetic equation shown below.

$\mathrm{V}_{\mathrm{W}} \mathrm{D}_{\mathrm{W}}+\mathrm{V}_{\mathrm{O}} \mathrm{D}_{\mathrm{O}}+\mathrm{V}_{\mathrm{B}} \mathrm{D}_{\mathrm{B}}=\left(\mathrm{V}_{\mathrm{W}}+\mathrm{V}_{\mathrm{O}}+\mathrm{V}_{\mathrm{B}}\right) \cdot \mathrm{D}_{\mathrm{M}}=\mathrm{V}_{\mathrm{M}} \mathrm{D}_{\mathrm{M}}(6)$

Where; $\mathrm{V}_{\mathrm{W}}=$ volume of water, $\mathrm{V}_{\mathrm{O}}=$ volume of oil, $\mathrm{V}_{\mathrm{B}}=$ volume of bentonite, $\mathrm{D}_{\mathrm{W}}=$ density of water, $\mathrm{D}_{\mathrm{O}}=$ density of oil, $\mathrm{D}_{\mathrm{B}}=$ density of bentonite and $\mathrm{D}_{\mathrm{M}}=$ final density of the mud

The total volume of mud required for the sample is $350 \mathrm{ml}$. The percentage of oil to distilled water ratio in the mud sample is $80 \%$ to $20 \%$. In order to make the mud, the materials required are bentonite, Jatropha oil, which formed the base oil and distilled water. The apparatus used for the mud preparation are the measuring cylinder, the weighing balance to accurately measure the ingredients, a petri dish, dropper, conical flask, the Hamilton Beach mixer, marsh funnel, beaker, digital thermometer and pipette. During the experimental stage, sources of error such as parallax error in measuring the volume of samples from measuring cylinders was avoided, when measurements were taking using the measuring cylinder, the reading was taking from the bottom meniscus. While the bentonite to be used was being measured, the mass of the petri dish was also considered and deducted from the total mass. During stirring of the mixture, the speed of the Hamilton beach mixer was set to low in order to prevent spillage of the mixture.

\subsection{Mud Weight or Density}


Density is defined as the mass per unit volume as shown below

Density, $\rho=\frac{\text { Mass, } m}{\text { Volume, } V}(7)$

Controlling the density of the drilling fluid system is important to provide adequate hydrostatic head. The hydrostatic head of drilling fluids prevents influx of formation fluids hence it is necessary to know the density of the fluid. The value must not be too high as to cause loss of circulation, which could result in destruction of the formation. The normal value for pressure gradient by water is about $0.433 \mathrm{psi} / \mathrm{ft}$. (433 psi/1000ft). The calibrated values of the mud balance which is the apparatus used to measure the mud weight or density is as shown below.

$\mathrm{P}=0.052 \times \rho \times \mathrm{h}$

Where, $\mathrm{P}=$ pressure (psi), $\rho=$ mud weight or density $(\mathrm{ppg})$ and $\mathrm{h}=$ formation depth (ft.)

\subsection{Marsh Funnel Viscosity}

The marsh funnel viscosity however is the time measured in seconds it takes for one quart of the drilling mud sample to flow out of the funnel into the cup.

Viscosity, $\mu=\frac{\text { Force, } F}{\text { Area, } A \times \text { Time, } s}$

The gel strength signifies the amount of pump pressure that would be required to circulate the mud after a shutdown period.

For Newtonian fluids such as water,

$$
\text { Shear-stress, } \tau
$$

$=$ Absolute Viscosity, $\mu \times$ Shear - rate, $\gamma(9)$

While for Non Newtonian fluids there are two model equations namely:

The Bingham plastic model:

$$
\begin{array}{r}
\text { Shear }- \text { stress, } \tau \\
=\text { Yield stress }+(\text { Plastic Viscosity, } \mu \times \text { Shear }- \text { rate } \gamma)(10)
\end{array}
$$

The Power law model:

Shear - stress, $\tau=k^{\prime} \times($ Shear - rate $\gamma) \mathrm{n}(11)$

The temperature of the sample was measured using a digital thermometer. Room temperature was $24^{\mathrm{O}} \mathrm{C}$, the original temperature of the mud sample was $22.4^{\mathrm{O}} \mathrm{C}$. When the target temperature of $30^{\mathrm{O}} \mathrm{C}$ was achieved, the sample was taken off the hotplate and transferred to the viscometer. The sample was mixed on stir for 10 seconds, the temperature was noted and then the knob was rotated to 600rpm. When the dial on the scale settled, a reading was taking and the temperature noted again. This process was repeated for all speeds until 6rpm. A 10 second and 10 minute gel test was then carried out to show the amount of gelation that would occur in the event of ceased circulation and static mud. The mud was mixed for 10 seconds in stir mode after which the knob was rotated to gel mode and the power shut of simultaneously. After the sleeve stopped rotating, counted 10 seconds but positioned in a position to read the dial at about the 7th second so the once the power is turned on, maximum dial deflection before the gel broke can be noted. This exact same process was repeated for the 10-minute gel test.

Table 4: OFITE Viscometer viscosity reading for mud sample one 


\begin{tabular}{lll}
\hline RPM & VISCOSITY $(\mathrm{Cp})$ & TEMPERATURE $(\mathrm{OC})$ \\
\hline 600 & 305 & 31 \\
300 & 215 & 30.7 \\
200 & 158 & 31.7 \\
100 & 92 & 31 \\
60 & 88 & 31 \\
30 & 65 & 31 \\
6 & 25 & 30.4 \\
\hline
\end{tabular}

Plastic viscosity $(\mathrm{PV}), \mathrm{Cp}=90 \mathrm{Cp}$

Yield point (YP), lb./100ft2 = $125 \mathrm{Cp}$

Apparent viscosity (AV), Cp. $=152.5 \mathrm{Cp}$

Table 5: 10 seconds and 10 minute Gel strength test for mud sample one

\begin{tabular}{llll}
\hline GEL STRENGTH & MAX DEFLECTION & TEMPERATURE (OC) & $\mathrm{pH}$ \\
\hline 10 sec. gel & 3 & 27.5 & 9.7 \\
10 min. gel & 5 & 25 & \\
\hline
\end{tabular}

Table 6: OFITE Viscometer viscosity readings for mud sample 2

\begin{tabular}{lll}
\hline REVOLUTION PER MIN. & VISCOSITY $(\mathrm{Cp})$ & TEMPERATURE $(\mathrm{OC})$ \\
\hline 600 & 30 & 29.2 \\
300 & 20 & 29 \\
200 & 15 & 27.5 \\
100 & 10 & 27.5 \\
60 & 8 & 27.5 \\
30 & 6 & 26 \\
6 & 4 & 26 \\
\hline
\end{tabular}

Table 7: 10 seconds and 10 minute Gel strength test for mud sample two

\begin{tabular}{llll}
\hline GEL STRENGTH & MAX DEFLECTION & TEMPERATURE (OC) & $\mathrm{pH}$ \\
\hline 10 sec. gel & 3 & 27.5 & 9.7 \\
10 min. gel & 5 & 25 & \\
\hline
\end{tabular}

From the equations above we see that

$\mu \mathrm{p}=\phi 600-\phi 300$

$\mu \mathrm{a}=\frac{\phi 600}{2}$

Where, $\mu$ p is the plastic viscosity $(\mathrm{Cp})$, which is the slope of the shear stress $(\tau)$ vs. shear rate $(\gamma)$ curve for both the Bingham and the Newtonian models. $\mu \mathrm{a}$ is the apparent viscosity $(\mathrm{Cp}), \phi 600$ is the viscometer reading at $600 \mathrm{rpm}, \phi 300$ is the viscometer reading at $300 \mathrm{rpm}$.

The Newtonian curve intercepts at $(0,0)$ and would have a straight line curve, $\tau=\mu \mathrm{p} \gamma$ while the Bingham 
curve intercepts at $(0, X)$ and would have a straight line curve, $\tau=\mu p \gamma+X$ where $X$ is the yield point of the fluid and a point on the Y-axis. A Non-Newtonian fluid lies between the Newtonian and Bingham curves.

\subsection{Drill Bench Numerical analysis Results}

The hydraulics and kick section of the drill bench SPT software were used to perform steady state computations of the hydraulic and kick parameters in an oil well during drilling operations.

\subsubsection{Formation}

The formation parameters shown in table 16, which described the environment where the well is going to be drilled, were then entered.

Table 8: Well formation data

\begin{tabular}{llll}
\hline Lithology name & Top TVD $(\mathrm{m})$ & Bottom TVD $(\mathrm{m})$ & $\begin{array}{l}\text { Geothermal gradient } \\
(\mathrm{C} / \mathrm{m})\end{array}$ \\
\hline FORMATION & 0 & 60 & 4.3025 \\
& 60 & 199.8 & 1.846566524 \\
199.8 & 397.2 & 1.30775076 \\
397.2 & 568.4 & 1.507885514 \\
568.4 & 758.7 & 1.356542302 \\
& 758.7 & 902.1 & 1.800209205 \\
902.1 & 1045.4 & 1.801465457 \\
& 1045.4 & 1900.3 & 0.301965142 \\
& 1900.3 & 2000.2 & 2.584084084 \\
\hline
\end{tabular}

After entering the data, a graph of the formation was produced by drill bench as shown below. 


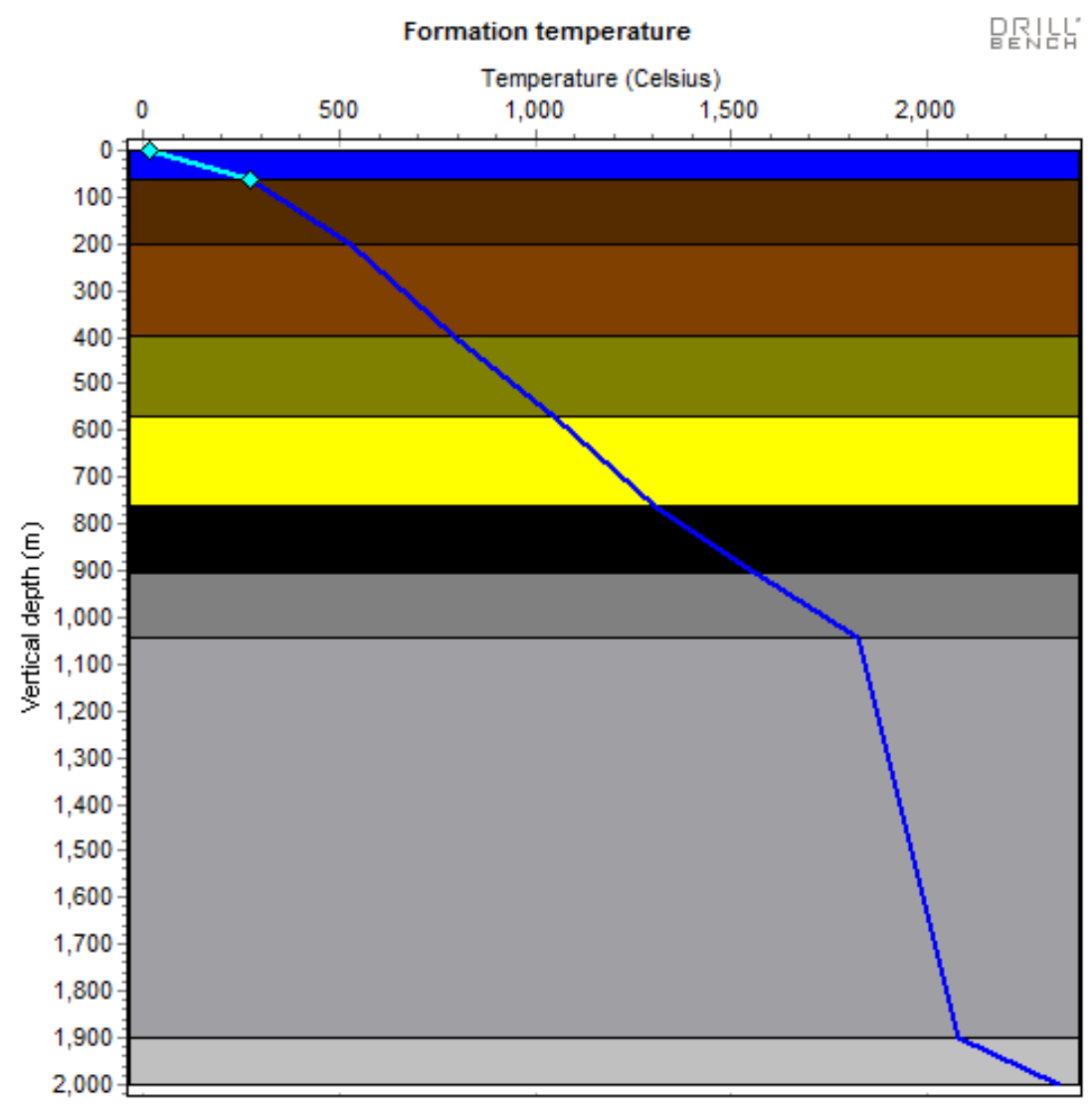

Figure 6: Well formation graph

\subsubsection{Survey}

The values for the survey are then entered and the simulator calculates the true vertical depth by using the minimum curvature algorithm. The below shows the data entered in this field.

Table 9: well survey data 


\begin{tabular}{|c|c|c|c|c|c|c|c|c|}
\hline & $\begin{array}{l}\text { Measured } \\
\text { depth }(m)\end{array}$ & \begin{tabular}{|l} 
Inclination \\
(deg)
\end{tabular} & \begin{tabular}{|l} 
Azimuth \\
(deg)
\end{tabular} & \begin{tabular}{|l|} 
Vertical \\
depth \\
$(\mathrm{m})$
\end{tabular} & North $(m)$ & East (m) & $\begin{array}{l}\text { Horizontal displacement } \\
\text { (m) }\end{array}$ & $\begin{array}{|ll|}\begin{array}{l}\text { Dogegeg } \\
(\mathrm{deg} / 30 \mathrm{~m})\end{array} & \text { Severity } \\
\end{array}$ \\
\hline 1 & 0 & 0 & 261.09 & 0 & 0 & 0 & 0 & 0 \\
\hline 2 & 60 & 0 & 261.1 & 60 & 0 & 0 & 0 & 0 \\
\hline 3 & 200 & 4.67 & 261.1 & $\begin{array}{l}199.8450 \\
394955\end{array}$ & -0.882208654233336 & -5.63366664943788 & 5.7023233884613 & \begin{tabular}{|l}
1.00071428571429 \\
\end{tabular} \\
\hline 4 & 400 & 13.33 & 261.1 & $\begin{array}{l}397.1947 \\
30412\end{array}$ & -5.71800981727562 & \begin{tabular}{|l|}
-36.5144470689174 \\
\end{tabular} & \begin{tabular}{|l|}
36.959443732546 \\
\end{tabular} & 1.299 \\
\hline 5 & 600 & 24 & 261.1 & $\begin{array}{l}586.4022 \\
364020\end{array}$ & -15.6062331584027 & \begin{tabular}{|l|}
-99.6593207808078 \\
\end{tabular} & \begin{tabular}{|l|}
100.873855541891 \\
\end{tabular} & 1.6005 \\
\hline 6 & 800 & 36.67 & 261.1 & $\begin{array}{l}758.6681 \\
822434\end{array}$ & -31.2018609739936 & \begin{tabular}{|l|}
-199.250917258733 \\
\end{tabular} & \begin{tabular}{|l|}
201.679161433915 \\
\end{tabular} & 1.9005 \\
\hline 7 & 1000 & \begin{tabular}{|l|}
51.33 \\
\end{tabular} & \begin{tabular}{|l|}
261.1 \\
\end{tabular} & \begin{tabular}{|l|}
902.1440 \\
213006
\end{tabular} & -52.6374502460481 & -336.135727687131 & \begin{tabular}{|l|l|}
340.232168667459 \\
\end{tabular} & \begin{tabular}{|l|}
2.199 \\
\end{tabular} \\
\hline 8 & 1363 & 81.59 & 261.1 & $\begin{array}{l}1045.443 \\
226631\end{array}$ & -103.527486793616 & \begin{tabular}{|l|}
-661.112704857973 \\
\end{tabular} & 669.169596624374 & 2.50082644628099 \\
\hline 9 & 7208 & 81.59 & 261.1 & $\begin{array}{l}1900.307 \\
716741\end{array}$ & -998.085786805886 & \begin{tabular}{|l|}
-6373.64254297949 \\
\end{tabular} & 6451.31726886084 & 0 \\
\hline 10 & 7582 & 67.36 & 261.1 & $\begin{array}{l}2000.155 \\
031128\end{array}$ & -1053.69314071047 & -6728.74367880772 & 6810.74597455192 & 1.14144385026738 \\
\hline
\end{tabular}

The software uses the well survey data entered to plot a well bore trajectory as shown in figure 7 below.

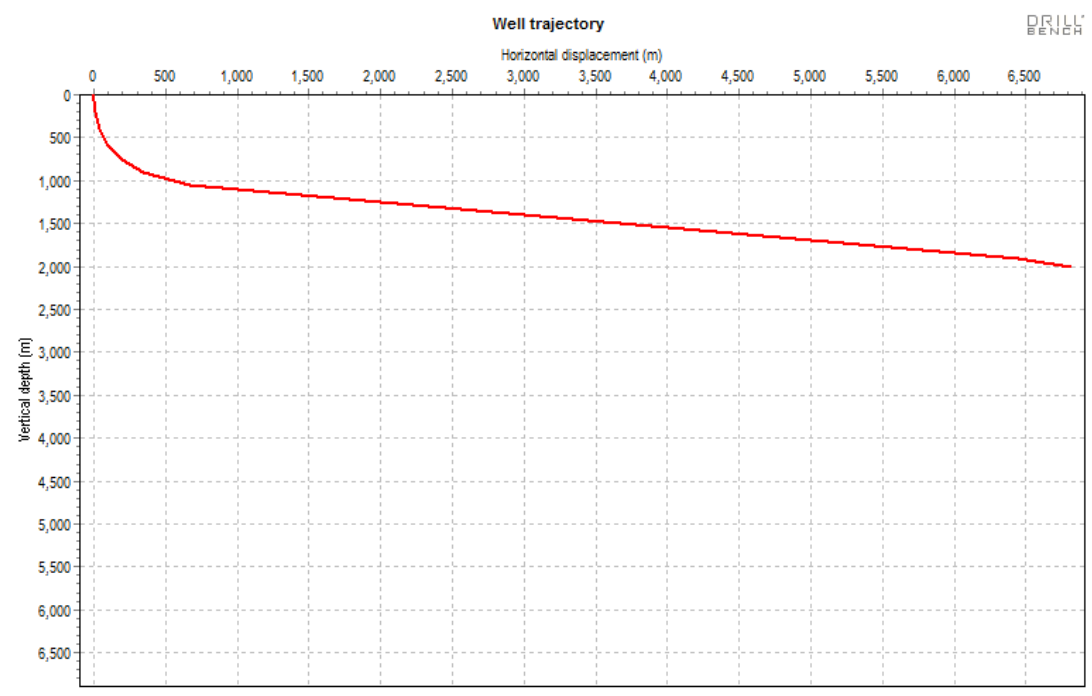

Figure 7: well bore trajectory 


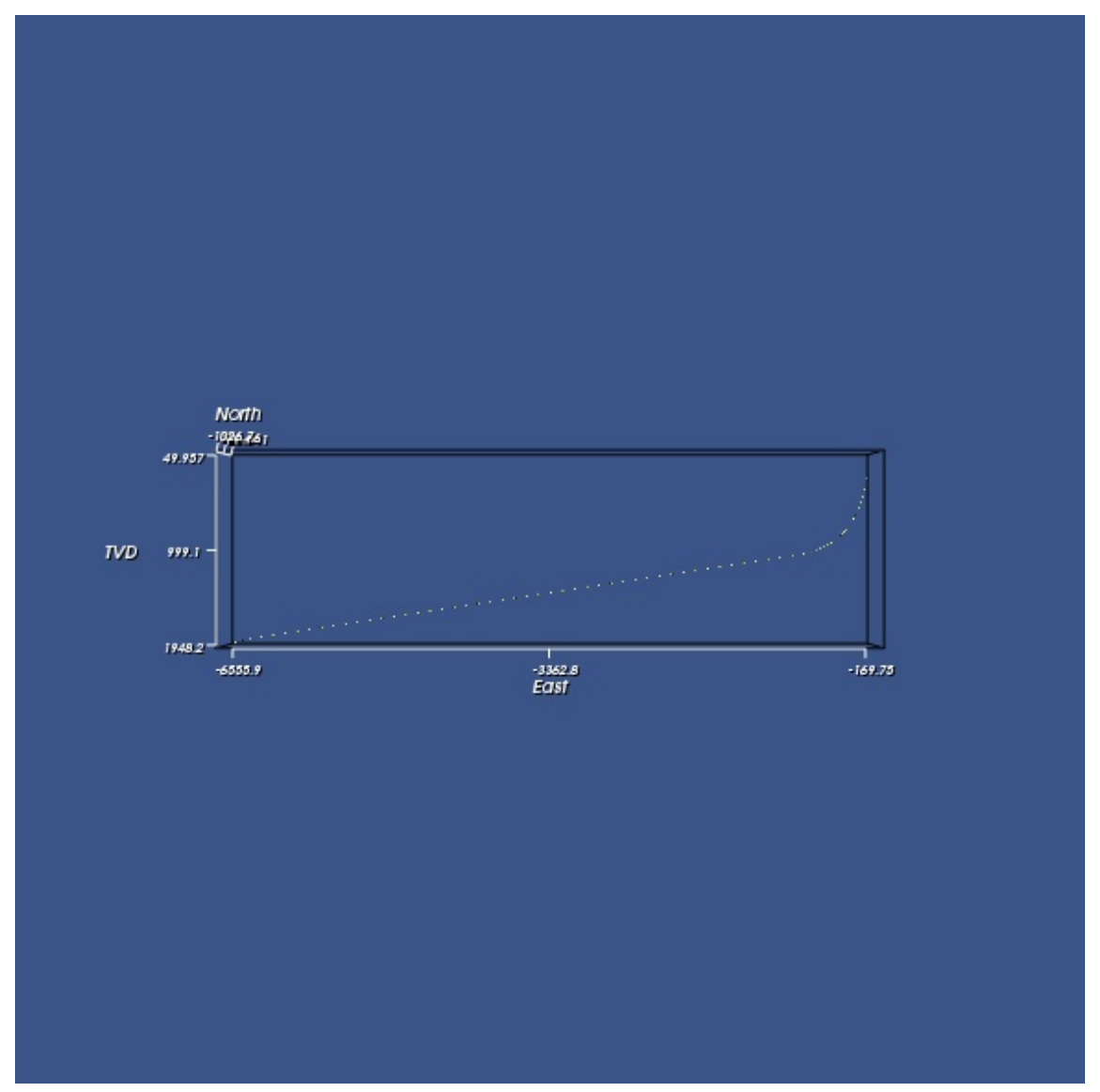

Figure 8: 3D well survey plot

\subsubsection{Fracture and Pore Pressure}

Table 10: Pore pressure

\begin{tabular}{llll}
\hline Measured depth $(\mathrm{m})$ & Vertical depth $(\mathrm{m})$ & Pore pressure gradient $(\mathrm{sg})$ & Pore pressure (bar) \\
\hline 60 & 60 & 2.306 & 14.58173094 \\
200 & 199.845039495546 & 2.367 & 47.4019611399882 \\
400 & 397.194730412391 & 2.3736 & 93.4685233503765 \\
600 & 586.402236402029 & 2.4346 & 141.018367754785 \\
800 & 758.668182243474 & 2.44360000000001 & 182.816926997169 \\
1000 & 902.144021300653 & 2.5046 & 222.59547915286 \\
1363 & 1045.44322663152 & 2.5136 & 258.714957692459 \\
7208 & 1900.3077167412 & 2.5746 & 480.806763651605 \\
7582 & 2000.15503112838 & 2.5836 & 507.781748201287 \\
\hline
\end{tabular}

Table 11: Fracture pressure

\begin{tabular}{llll}
\hline Measured depth $(\mathrm{m})$ & Vertical depth $(\mathrm{m})$ & Pore pressure gradient $(\mathrm{sg})$ & Pore pressure (bar) \\
\hline 60 & 60 & 2.306 & 14.58173094 \\
200 & 199.845039495546 & 2.367 & 47.4019611399882
\end{tabular}




\begin{tabular}{llll}
\hline Measured depth $(\mathrm{m})$ & Vertical depth $(\mathrm{m})$ & Pore pressure gradient $(\mathrm{sg})$ & Pore pressure (bar) \\
\hline 400 & 397.194730412391 & 2.3736 & 93.4685233503765 \\
600 & 586.402236402029 & 2.4346 & 141.018367754785 \\
800 & 758.668182243474 & 2.44360000000001 & 182.816926997169 \\
1000 & 902.144021300653 & 2.5046 & 222.59547915286 \\
1363 & 1045.44322663152 & 2.5136 & 258.714957692459 \\
7208 & 1900.3077167412 & 2.5746 & 480.806763651605 \\
7582 & 2000.15503112838 & 2.5836 & 507.781748201287 \\
\hline
\end{tabular}

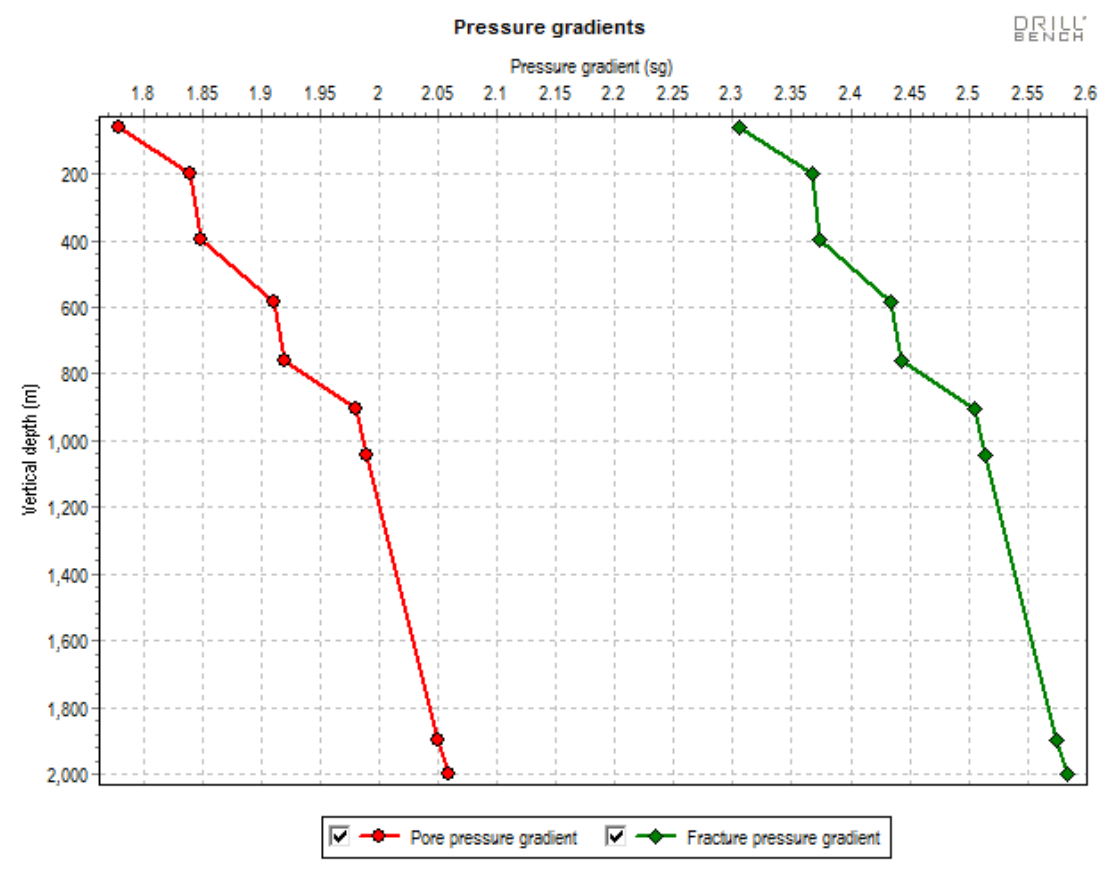

Figure 9: Pore and fracture pressures

\subsubsection{Wellbore Geometry}

This section is used to illustrate the types of casings used in the well construction.

Table 12: Riser specification

\begin{tabular}{llll}
\hline Name & Length $(\mathrm{m})$ & Inner diameter $(\mathrm{cm})$ & Outer diameter $(\mathrm{cm})$ \\
\hline 21” Riser & 60 & 48.26 & 53.34 \\
\hline
\end{tabular}




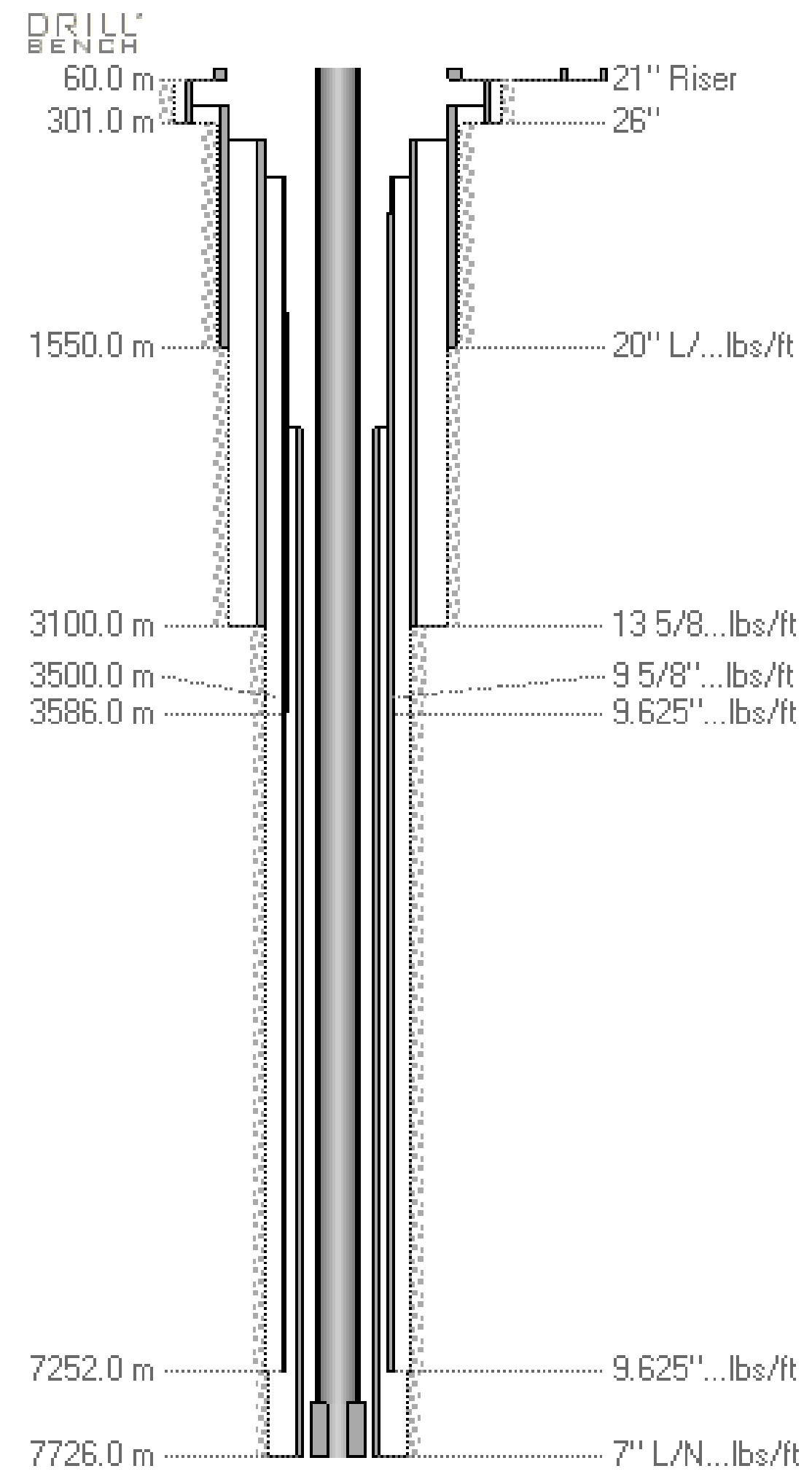


Figure 10: well schematic

\subsubsection{Drilling mud}

The appropriate drilling fluid was chosen from the library.

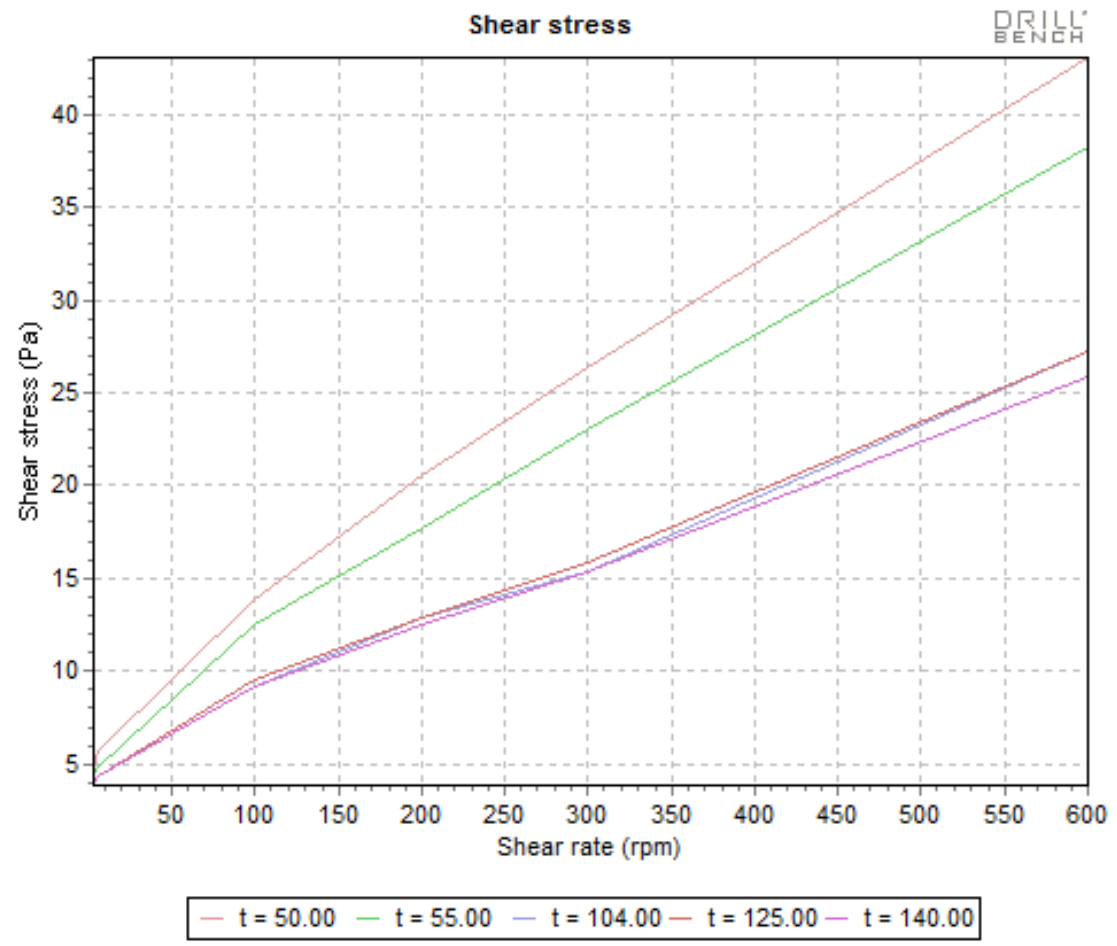

Figure 11: Drilling mud shear stress and shear rate graph 3.3.6 Temperature

The dynamic temperature model was used in this section. 


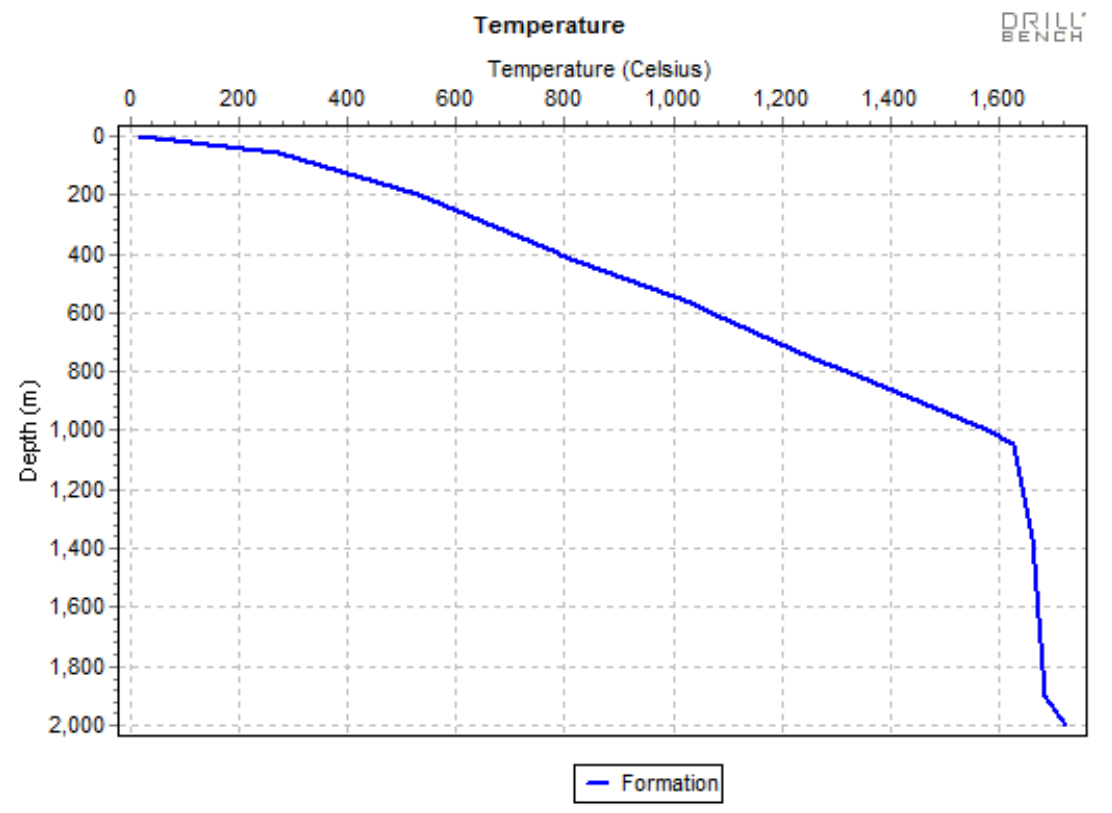

Figure 12: Dynamic temperature model of the formation

\subsubsection{Hydraulics}

The hydraulics window is used to calculate the modus operandi of the well. No slip is chosen in this section because it is assumed that the cuttings move at the same speed with the drilling fluid hence there is perfect hole cleaning. The results gotten from the calculations are shown below. The equivalent circulation density which is the density exerted by a circulating fluid against the formation is calculated using the equation below. It is very important in the avoidance of kick and losses.

$E C D=d+\frac{P}{0.052 * D}$

Where,

$\mathrm{D}=$ mud weight (ppg), $\mathrm{P}=$ pressure drop and $\mathrm{D}=$ true vertical depth

The graphs below show the pressure in the drill string, the annular pressure, the temperature, the equivalent viscosity, velocity, the cuttings velocity and transport ratio. 


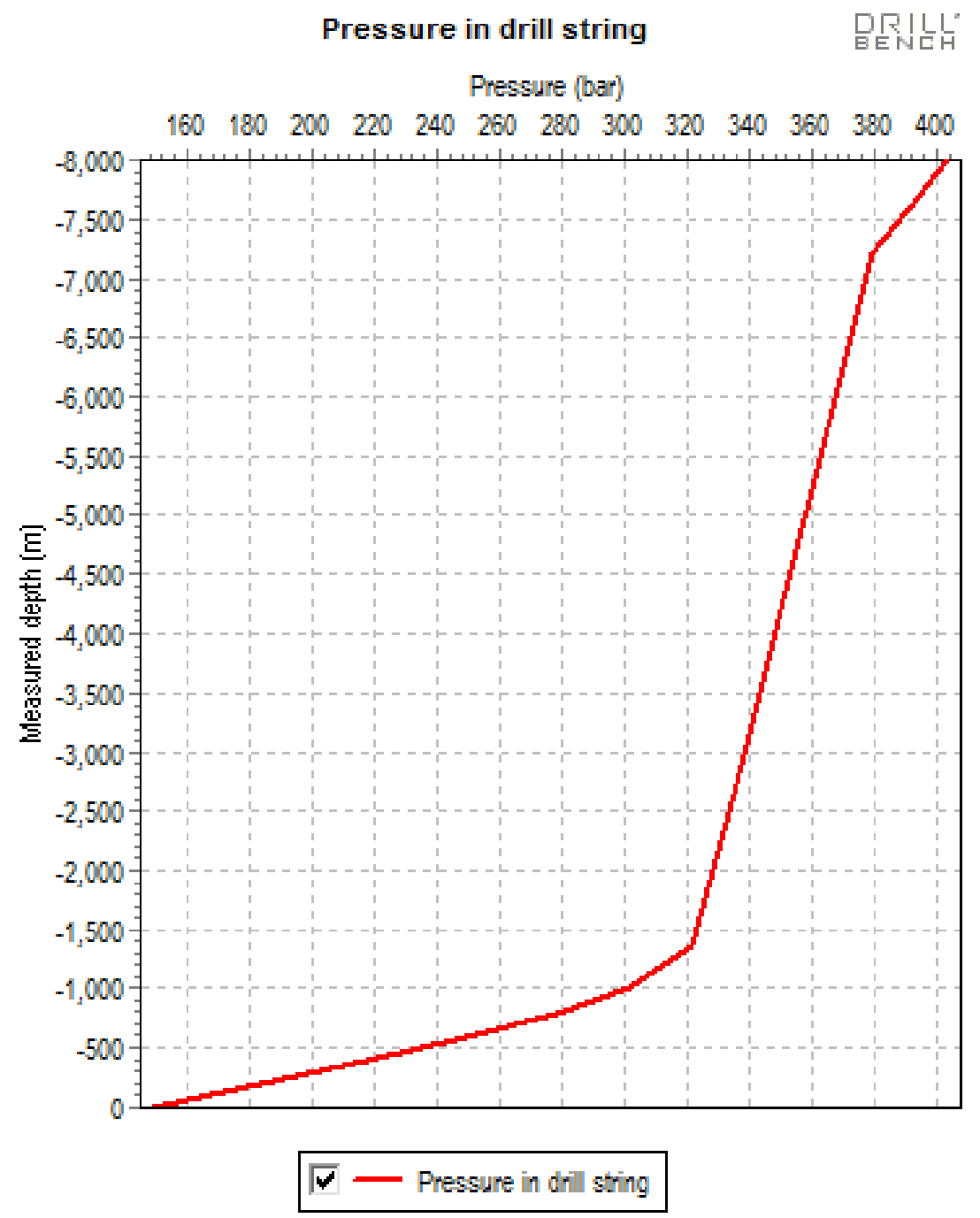

Figure 13: Pressure in the drill string 


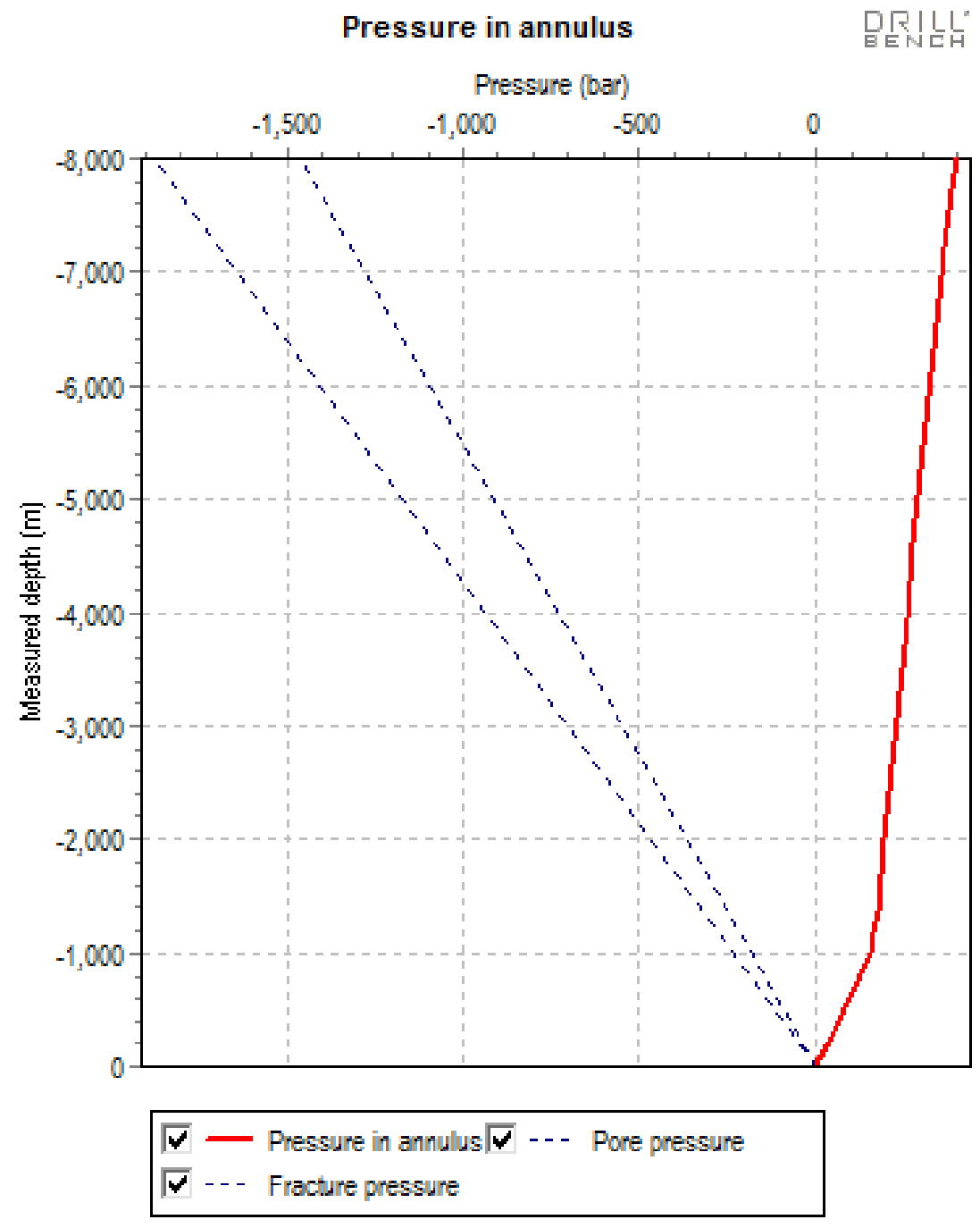

Figure 14: Annular pressure 


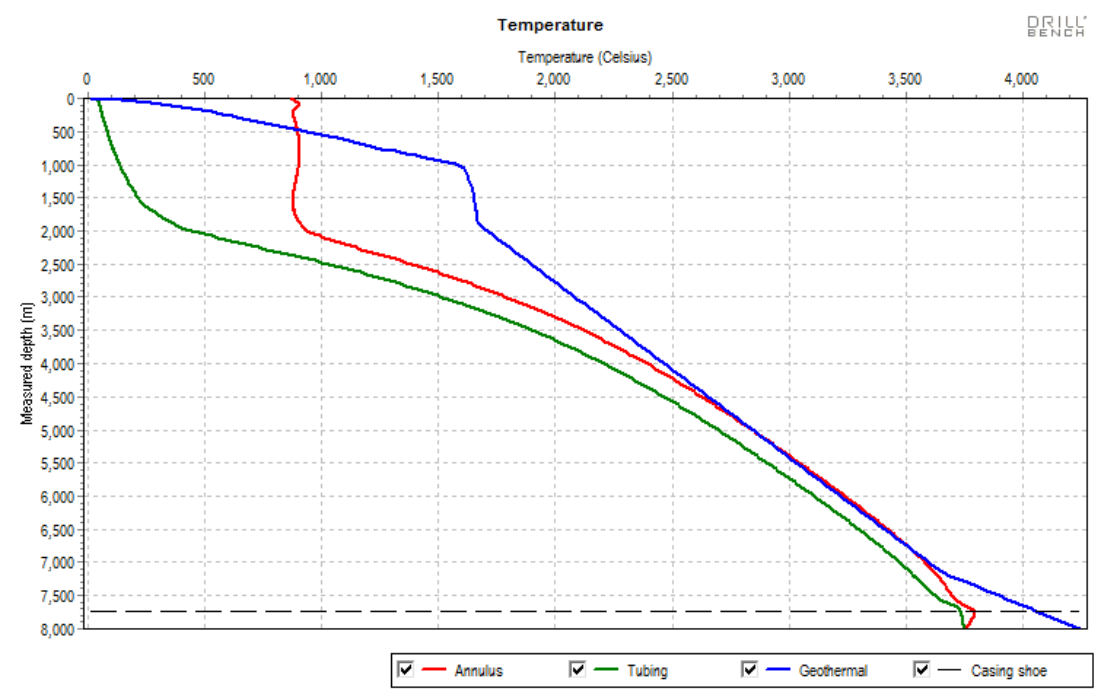

Figure 15: Hydraulic Temperature

The surge and swab section is used to calculate tripping limitations. It calculates the maximum string velocity, the return flow rate, the pressure and the equivalent circulation density.

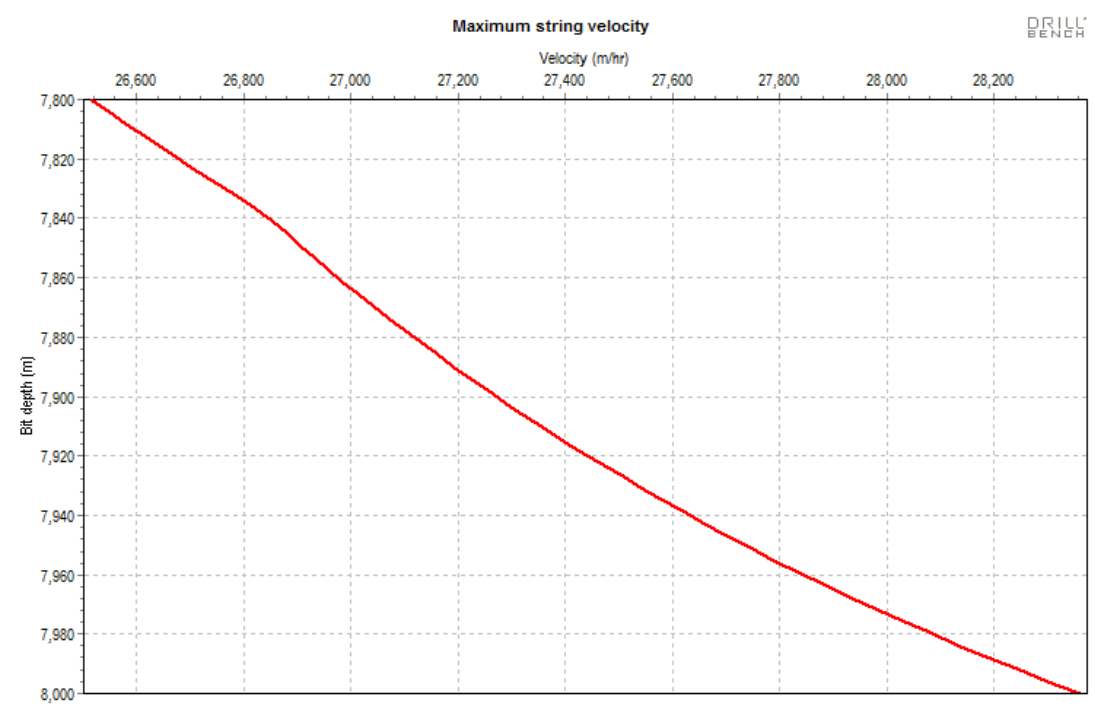

Figure 16: Maximum string velocity

The fixed pipe velocity calculated the well pressure at a selected tripping rate of $120 \mathrm{~m} / \mathrm{hr}$. The maximum tripping speed that must be reached without exceeding the pore and fracture pressure was determined by the surge and swab. 


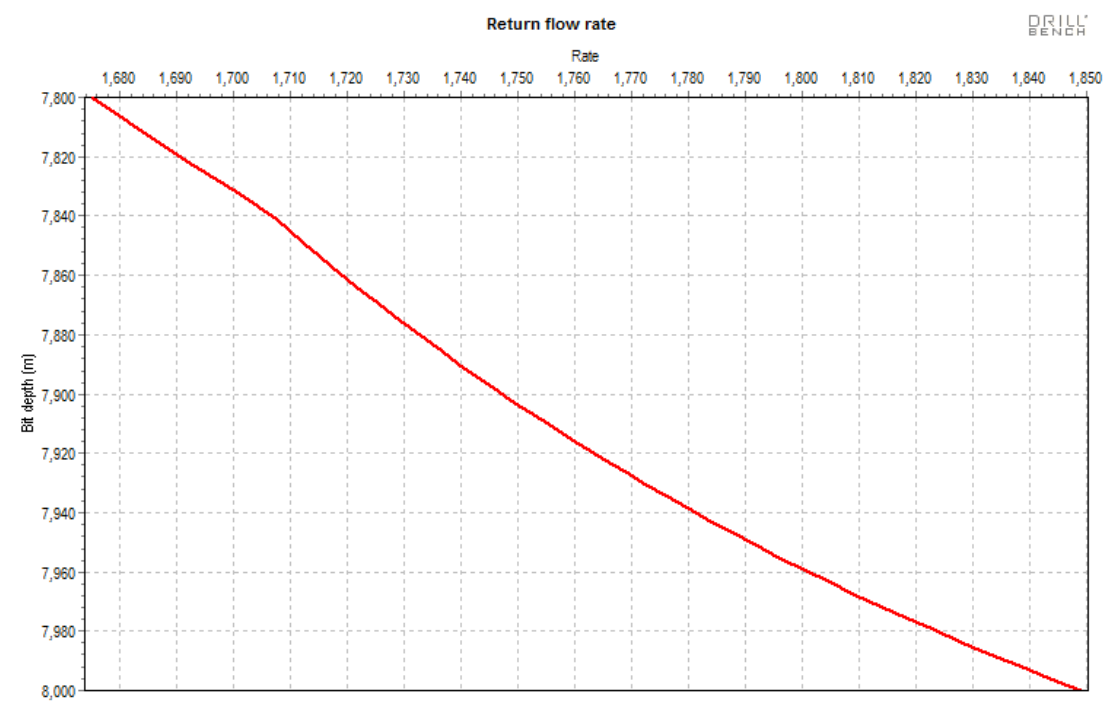

Figure 17: Return flow rate

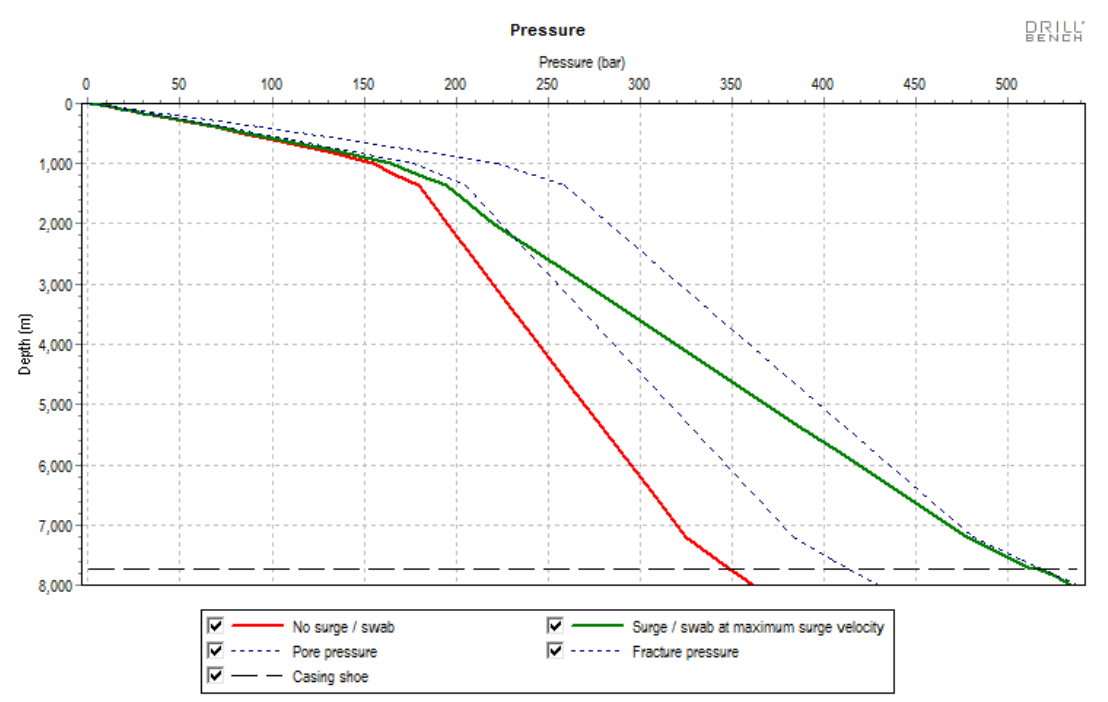

Figure 18: Pressure 


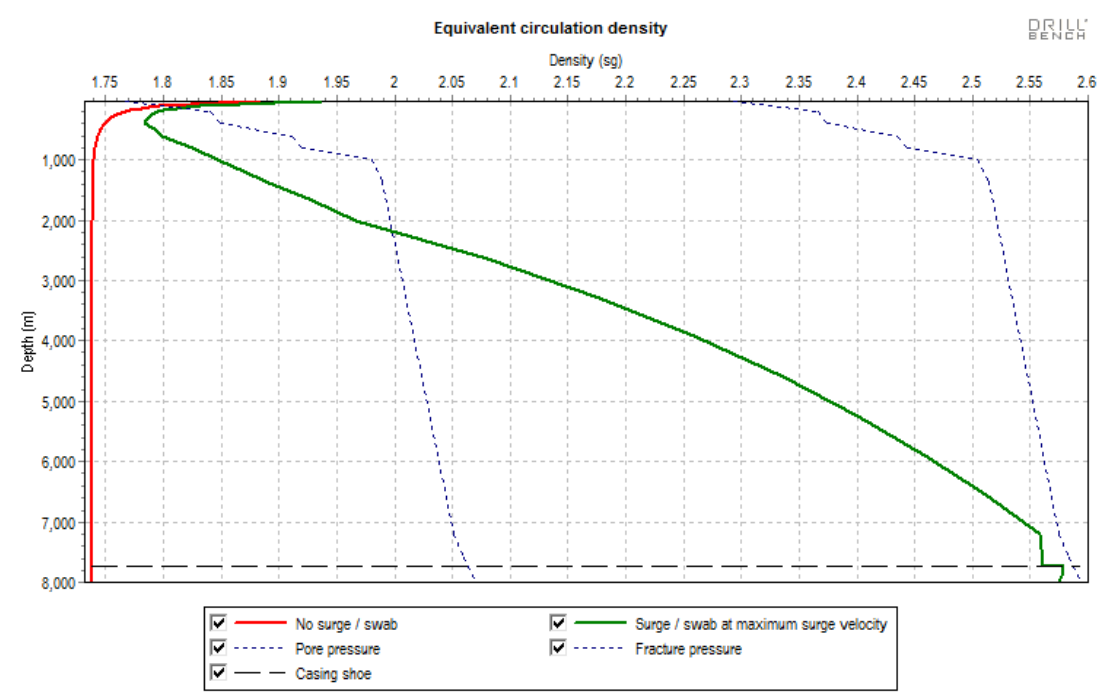

Figure 19: Equivalent circulation density

\subsubsection{Sensitivity analysis}

This is the calculation of hydraulic parameter by altering one input data. The input parameter altered here is the pump rate. The results gotten are as shown by the graphs below.

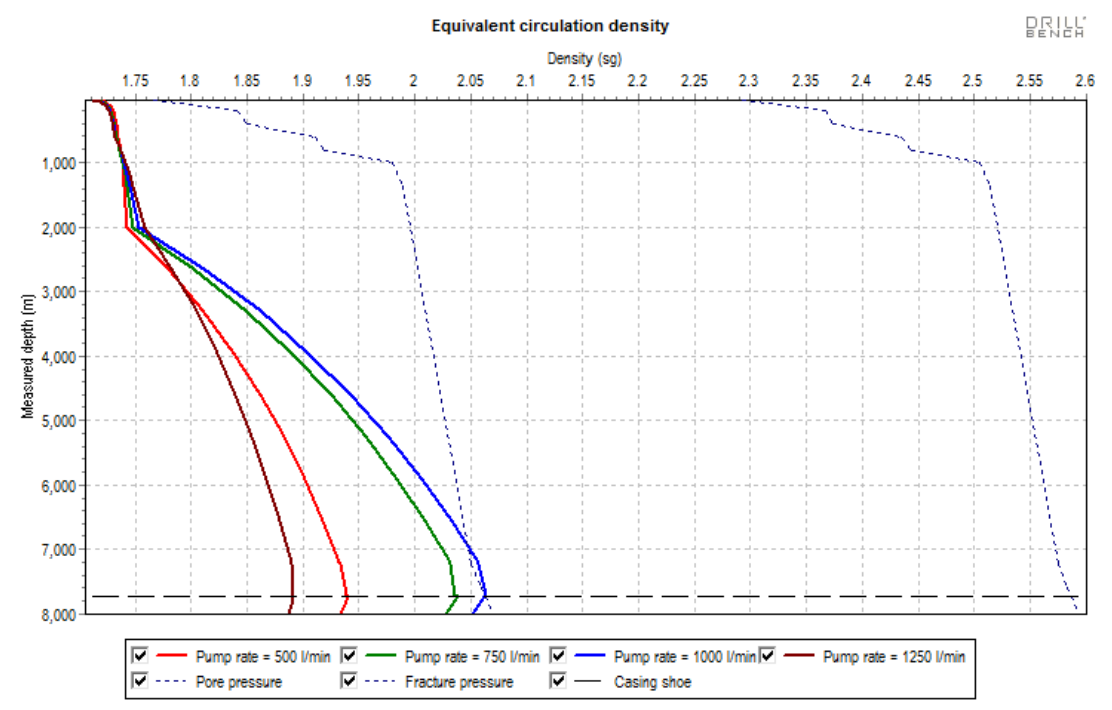

Figure 20: Equivalent circulation density 


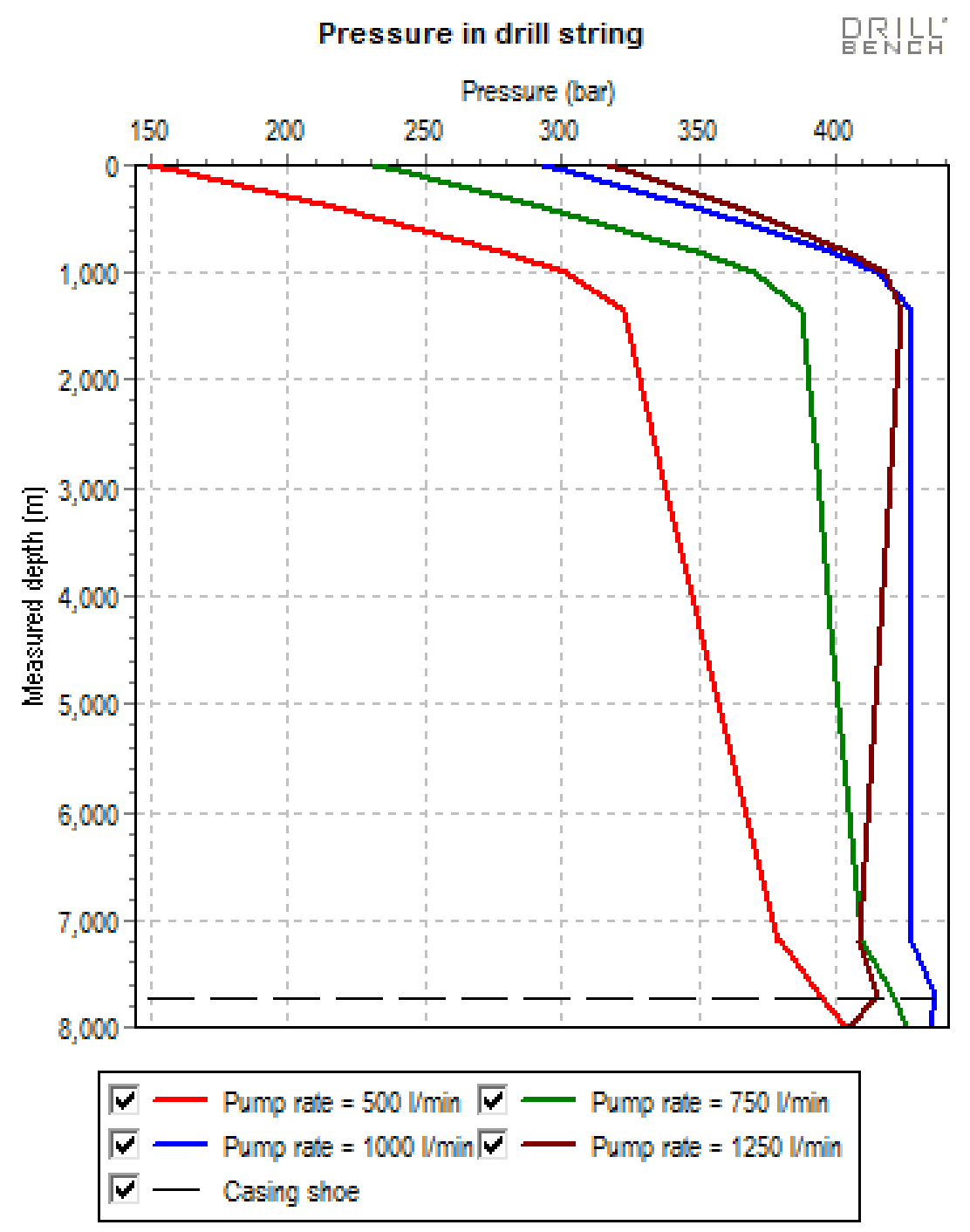

Figure 21: Drill string pressure 


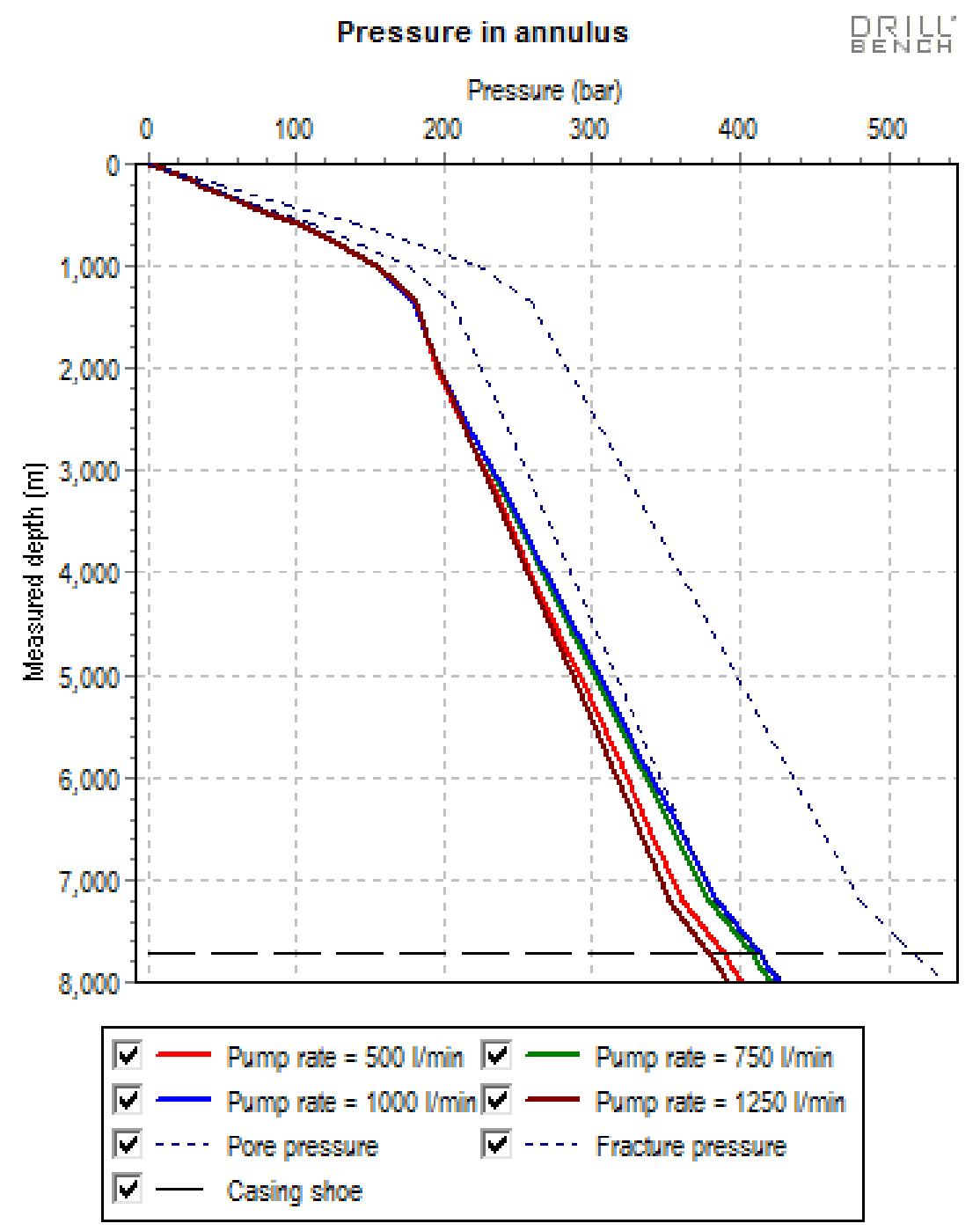

Figure 22: Annular pressure

Bit optimization was used to find the optimal bit nozzle size and pump rate as a function of bit depth. Drilling is most efficient at the optimal flow area and flow rate hence the bit size is optimized either by calculating the maximum bit hydraulic horsepower or by calculating the maximum jet impact force. It is seen that the jet impact force is about $90 \%$ of its maximum when the bit power is at maximum. 


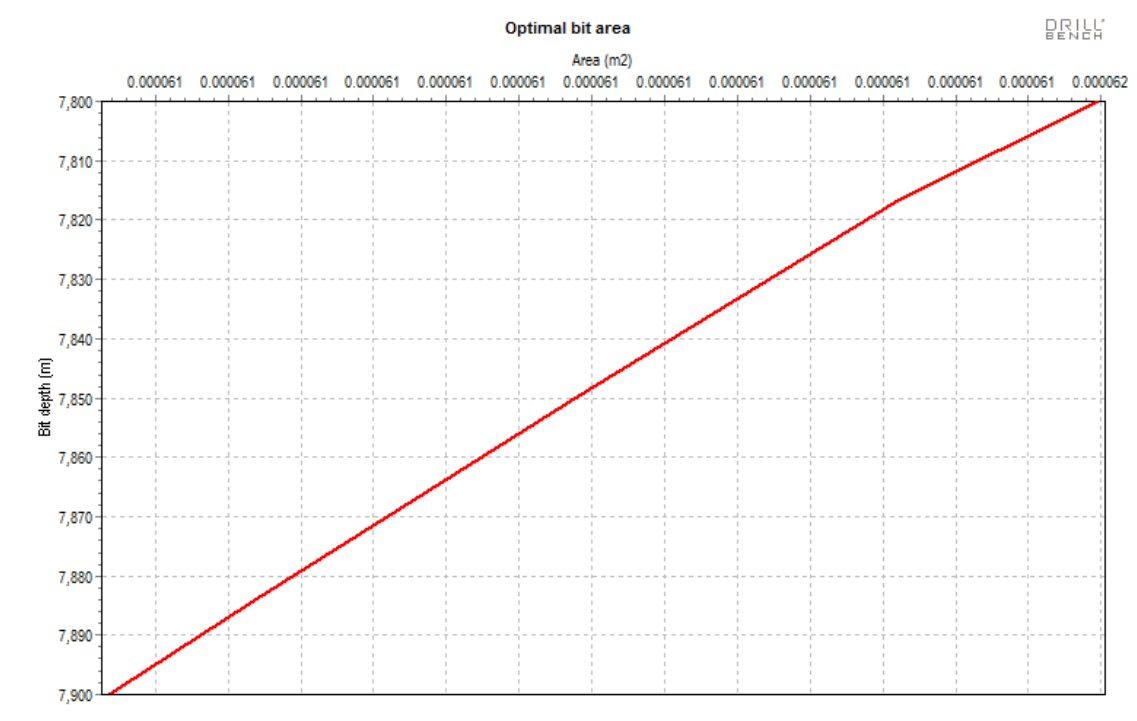

Figure 23: Bit Optimization graph

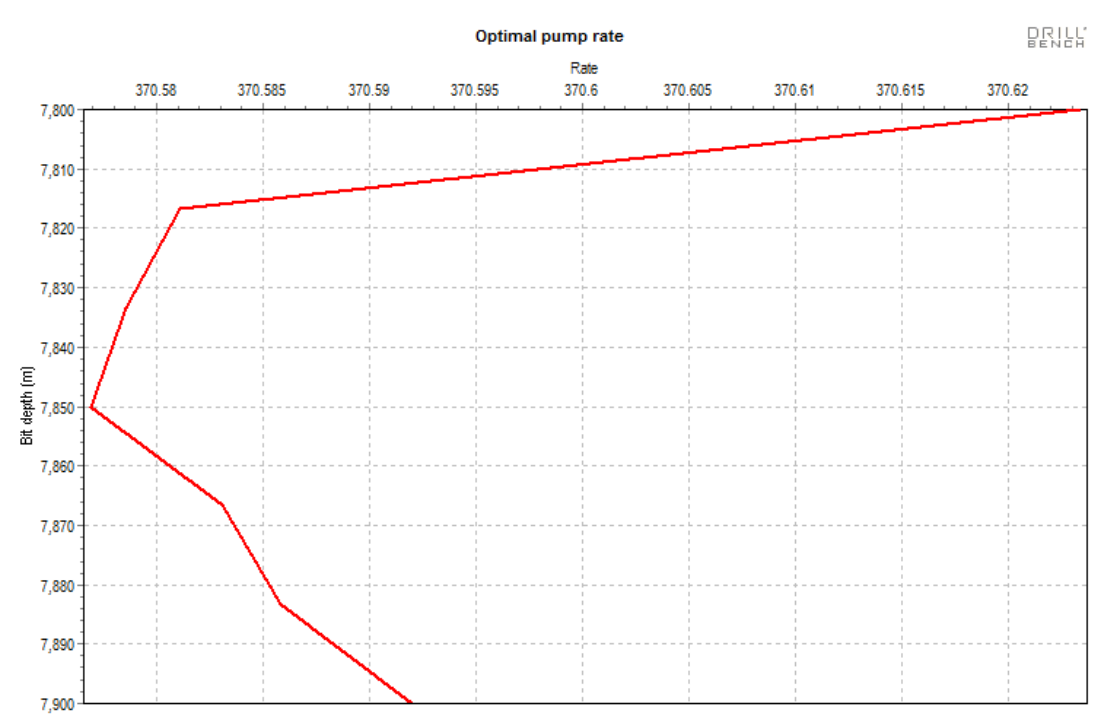

Figure 24: Optimal pump rate

Volumetric displacement helped determine the fluid front positions in the well and the pumped volume after a certain time. The fluids to be simulated, oil based mud sample and cement were chosen from the library. The graphs below show the fluid front positions in the well and the volume pumped respectively. The curves converged. 


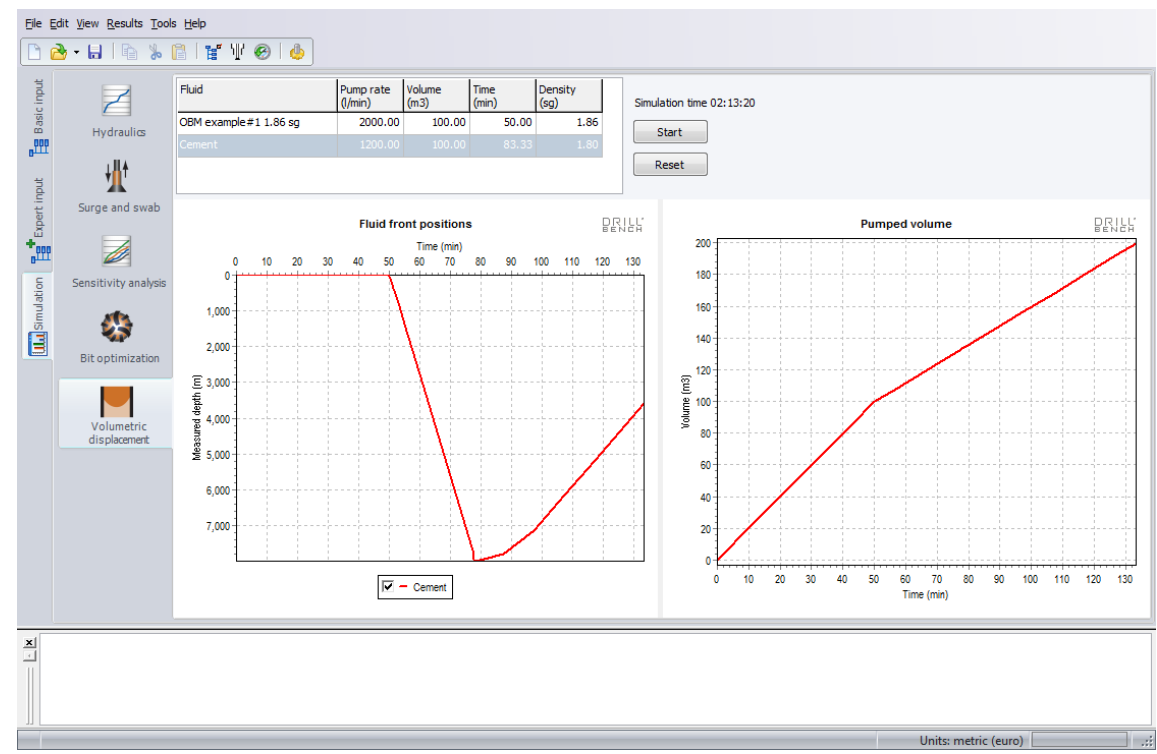

Figure 25: Volumetric displacement

\subsubsection{Kick module summary and description}

The kick simulation is used to detect how the flow of formation fluids into the wellbore during drilling due to pressure unbalance between formation and the wellbore can be prevented. The surface equipment section is used to describe the rig equipment and some of the parameters that would influence the drilling operation as shown in figure below.

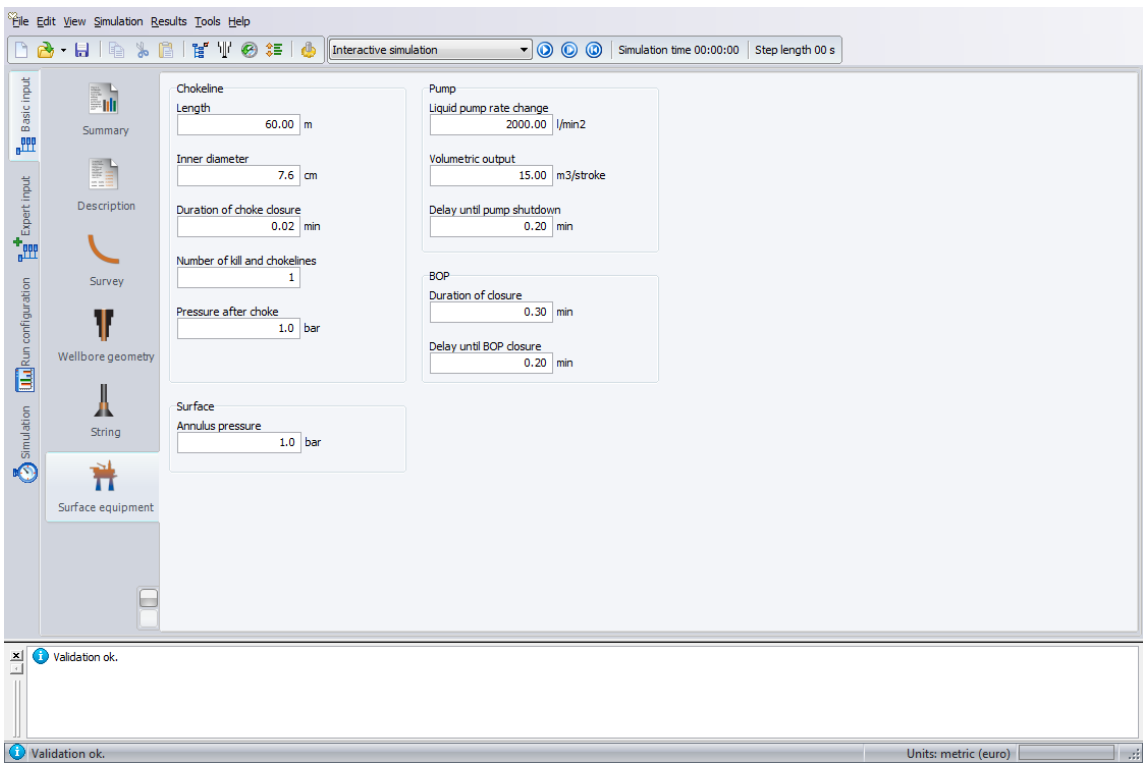

Figure 26: Surface equipment

The fracture pressure is needed to simulate the pressure needed for the formation and the wellbore to be balanced as shown below. 


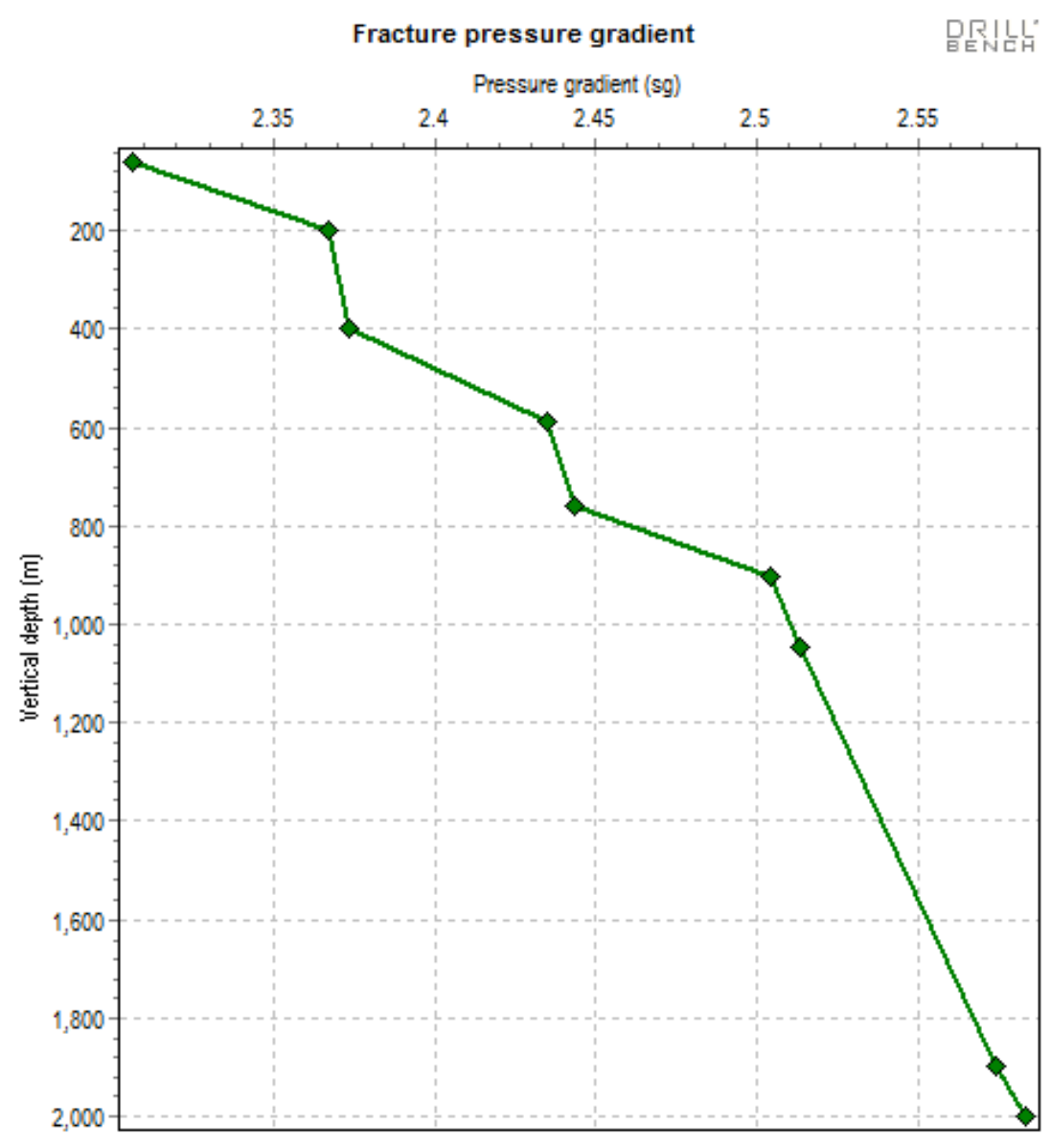

Figure 27: Fracture pressure graph

For the reservoir, it was necessary to know the type of influx fluid and the parameters that define the reservoir. The measured temperature data is entered into this widow in order to derive the wellbore temperature graph as shown below. 


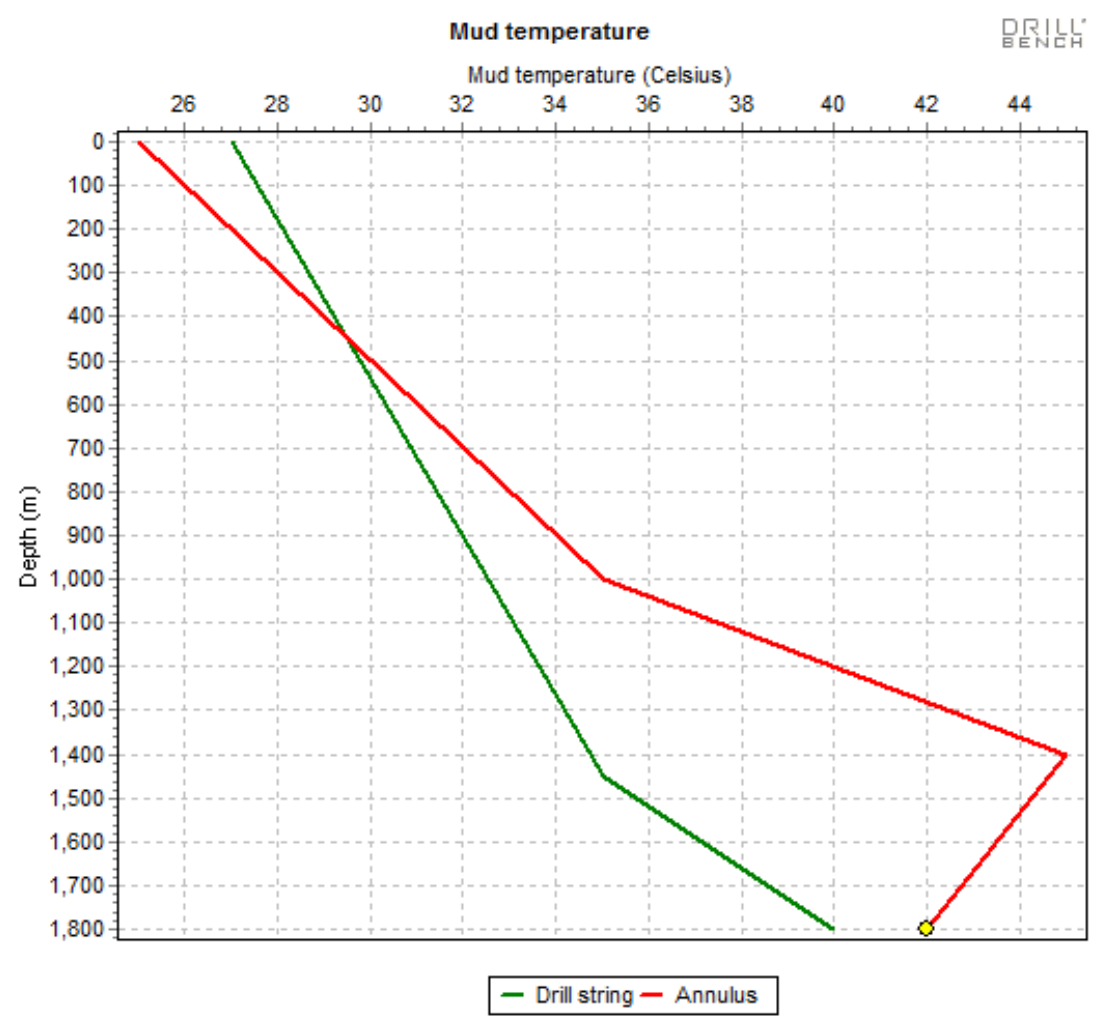

Figure 28: kick module temperature graph

Before simulation, the model parameters such as grid cell numbers and lost circulation data are entered. Simulating the kick the in the well bore required the setting of certain batch configurations which were allowed to run without any interference. The circulation rate before the pre-kick section defines kick while the degree of underbalance can be noted in the kick intensity. The sensitivity configuration calculated the maximum kick size, the casing show position and the degasser capacity as shown below. The simulation is run with the choke open and the results are recorded. Results of the simulation are shown below. 


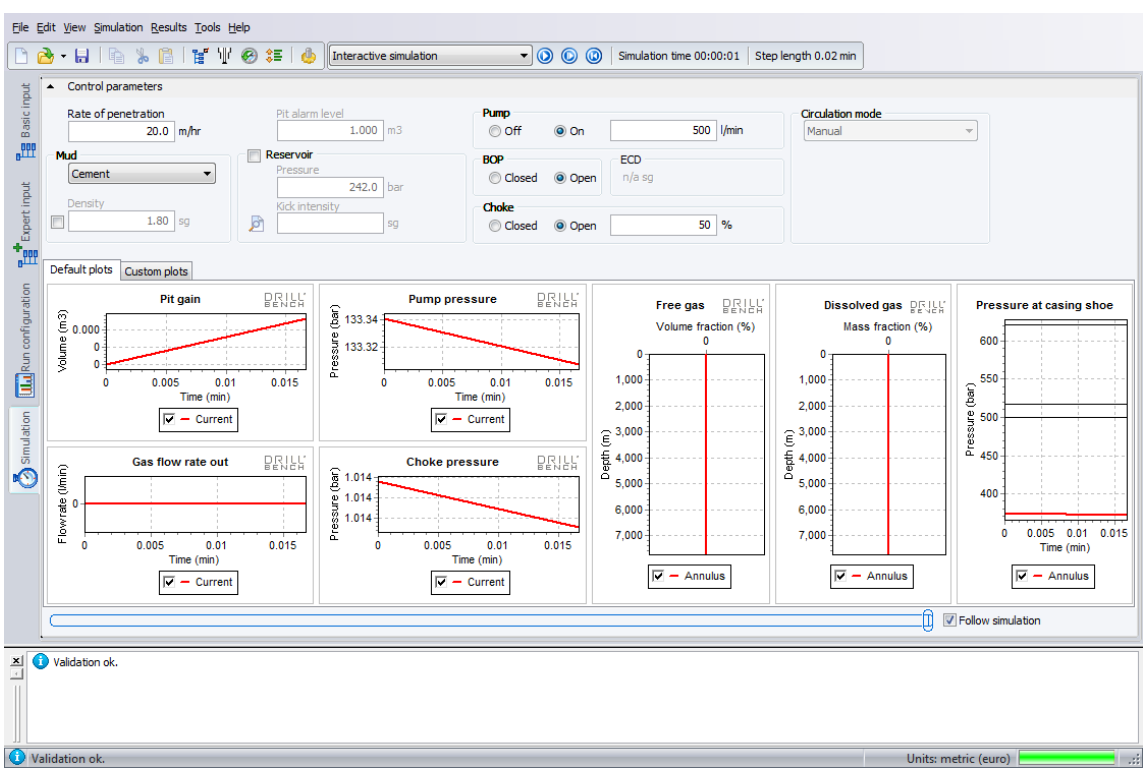

Figure 29: Simulation with choke open

When the choke was closed and the simulation run again, it was noticed that the choke line was not discretized and the reservoir pressure was less than the well pressure. The results are shown below.

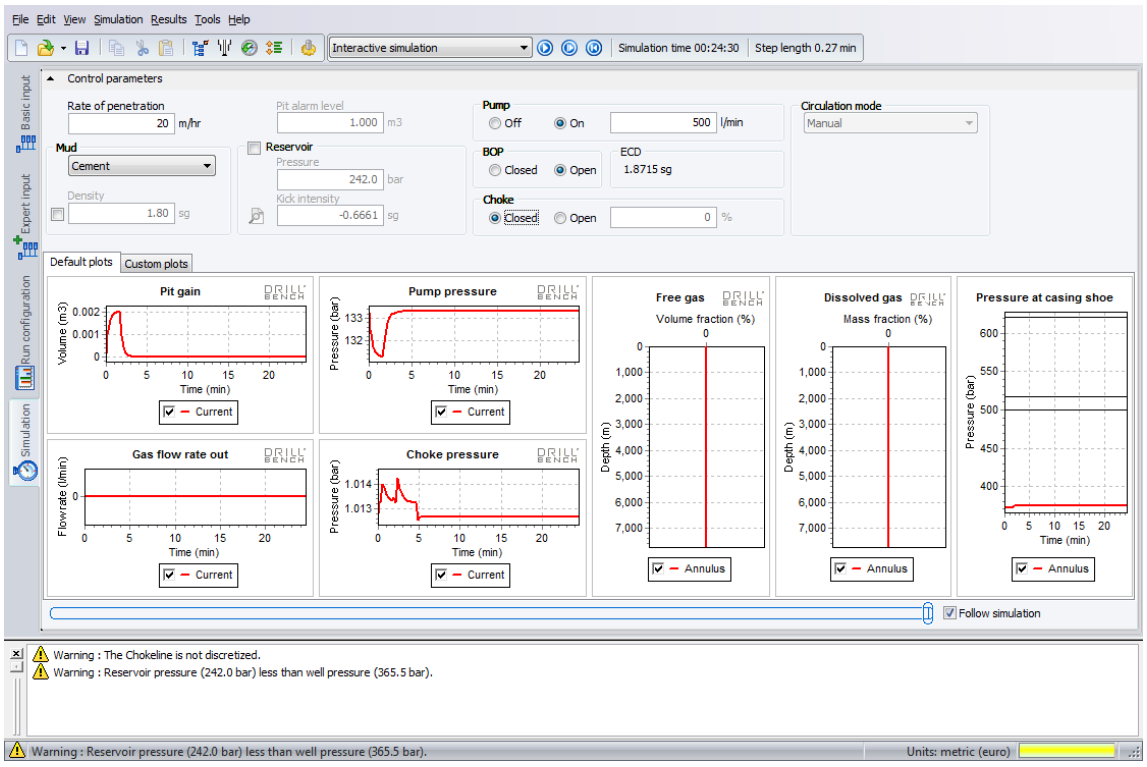

Figure 30: Simulation with choke closed

\subsection{Conclusion}

A drilling operation can only be successful if all tasks and activities are performed in an efficient manner. This means that the well must fully be under control at every time and this is only possible when engineers understand the role pressure relationships play in the wellbore and can detect when there is kick. Kick is the reason for the need for well pressure control. The results gotten from the simulation have shown us 
that the reservoir pressure is less than the well pressure hence there would be an influx of reservoir fluids into the formation meaning there is an overbalance. This is usually as a result of poor well planning. Lost circulation, insufficient mud density and swabbing or swabbing. In this case we are dealing with the use of invert emulsion muds to manage pressure control or kick hence the mud density has to be altered. This is because it does not exert enough hydrostatic pressure to match the well pressure which due to the extended reach of the well, it could be a problem of abnormally distributed pressure in the well. The aim and objectives of this paper have now been met as the rheological properties of Invert emulsion muds have been analysed and their use for pressure control stated.

\subsection{Appendix}

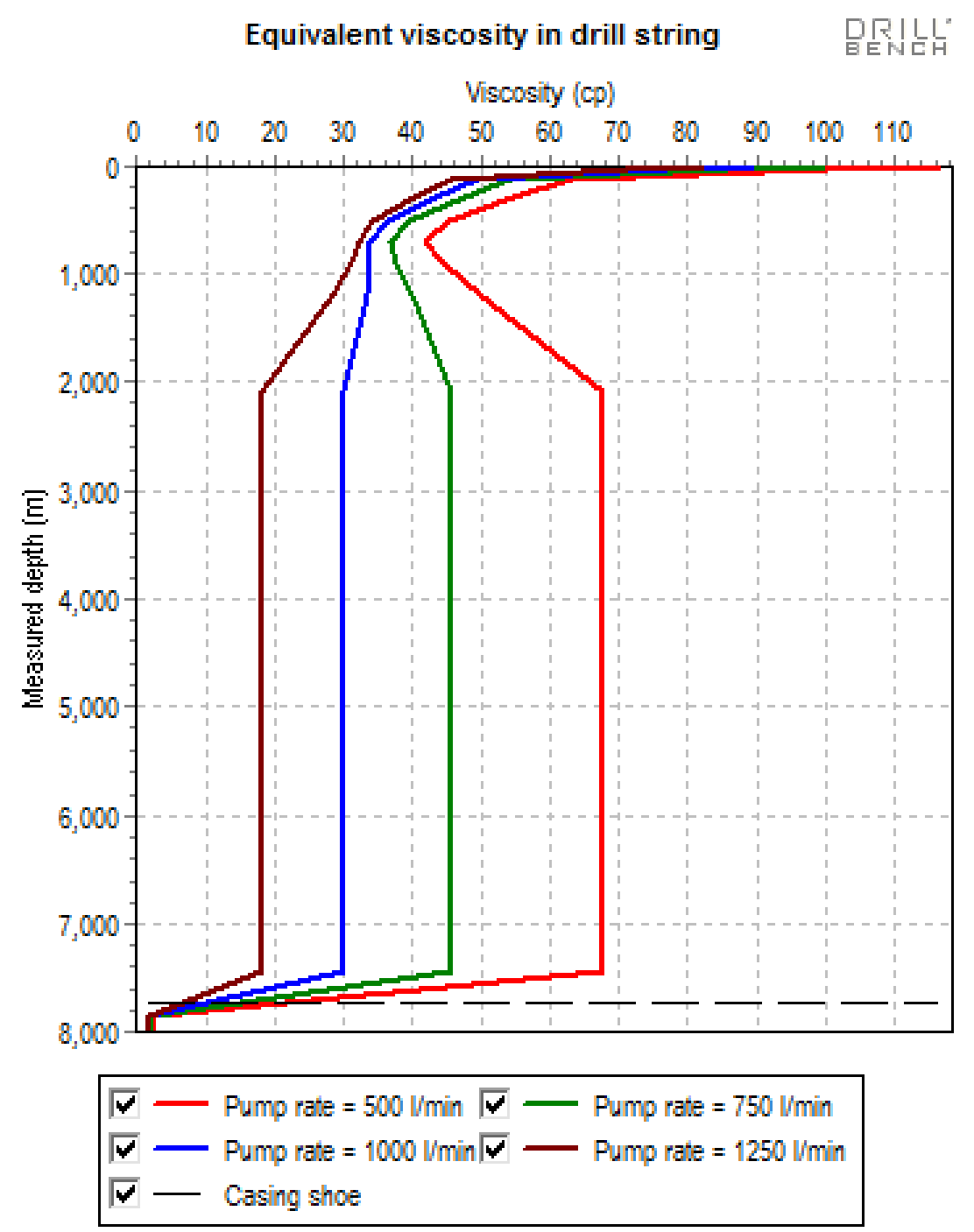

Figure 39: Equivalent viscosity 


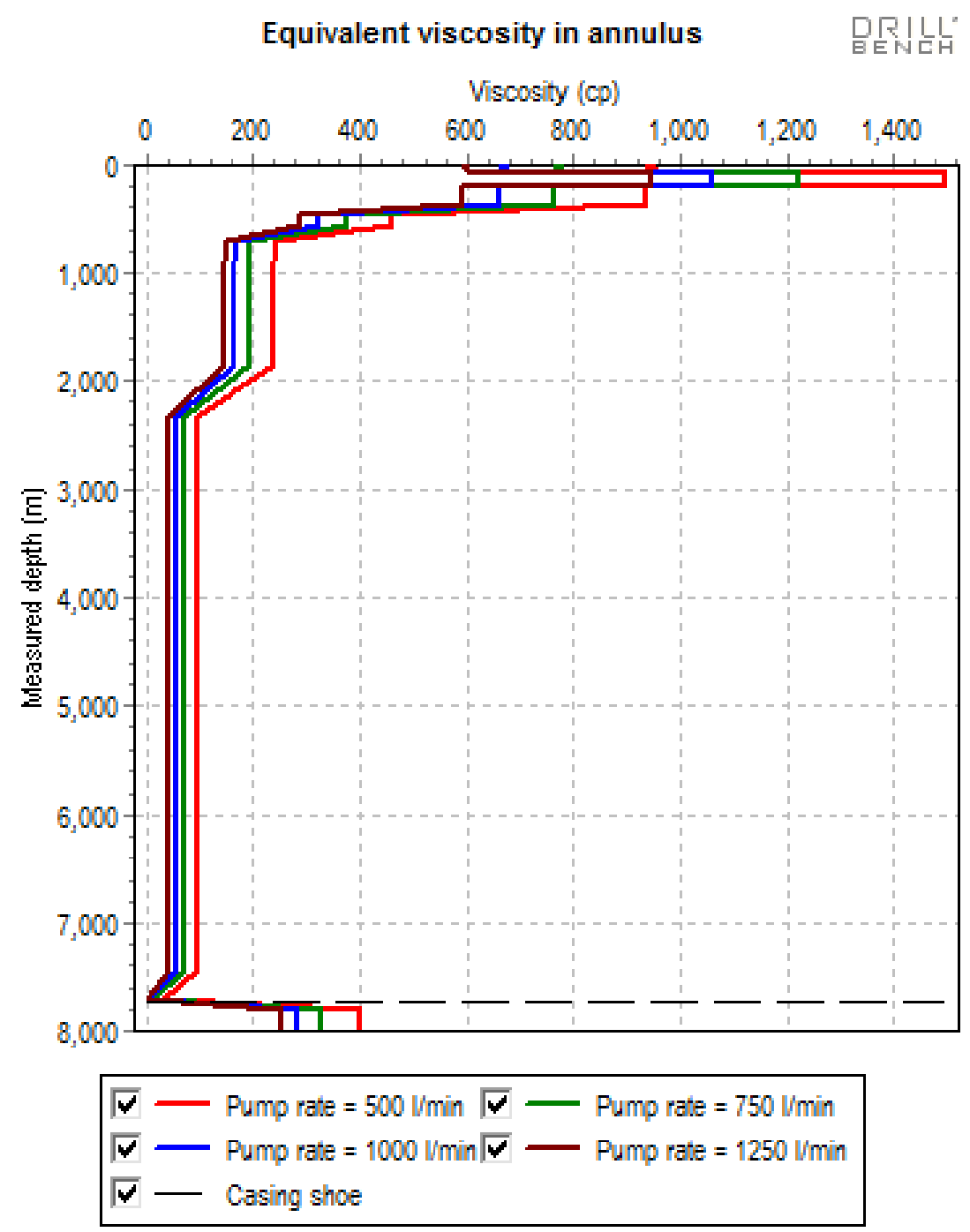

Figure 40: Annular equivalent viscosity 


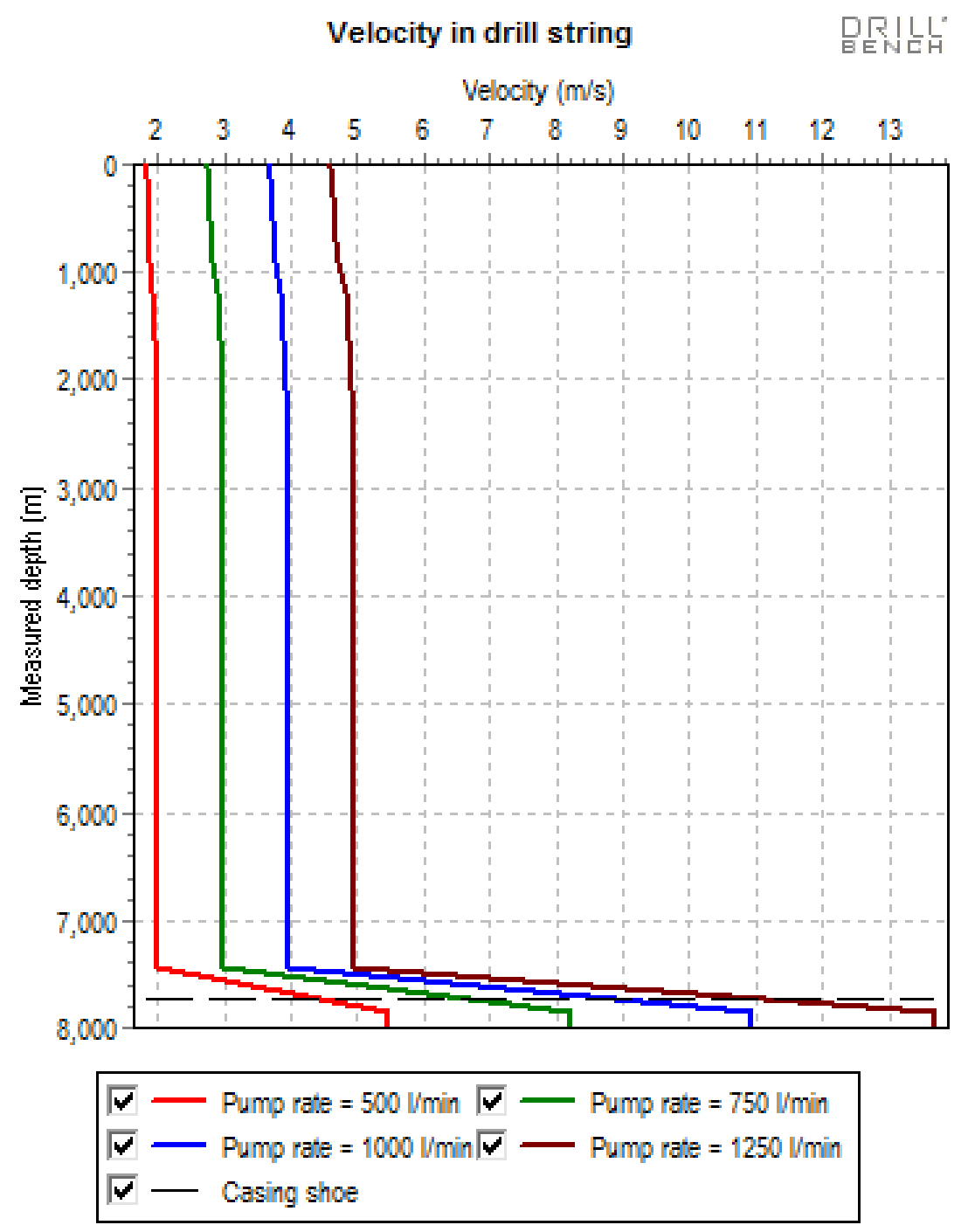

Figure 41: Drill string velocity 


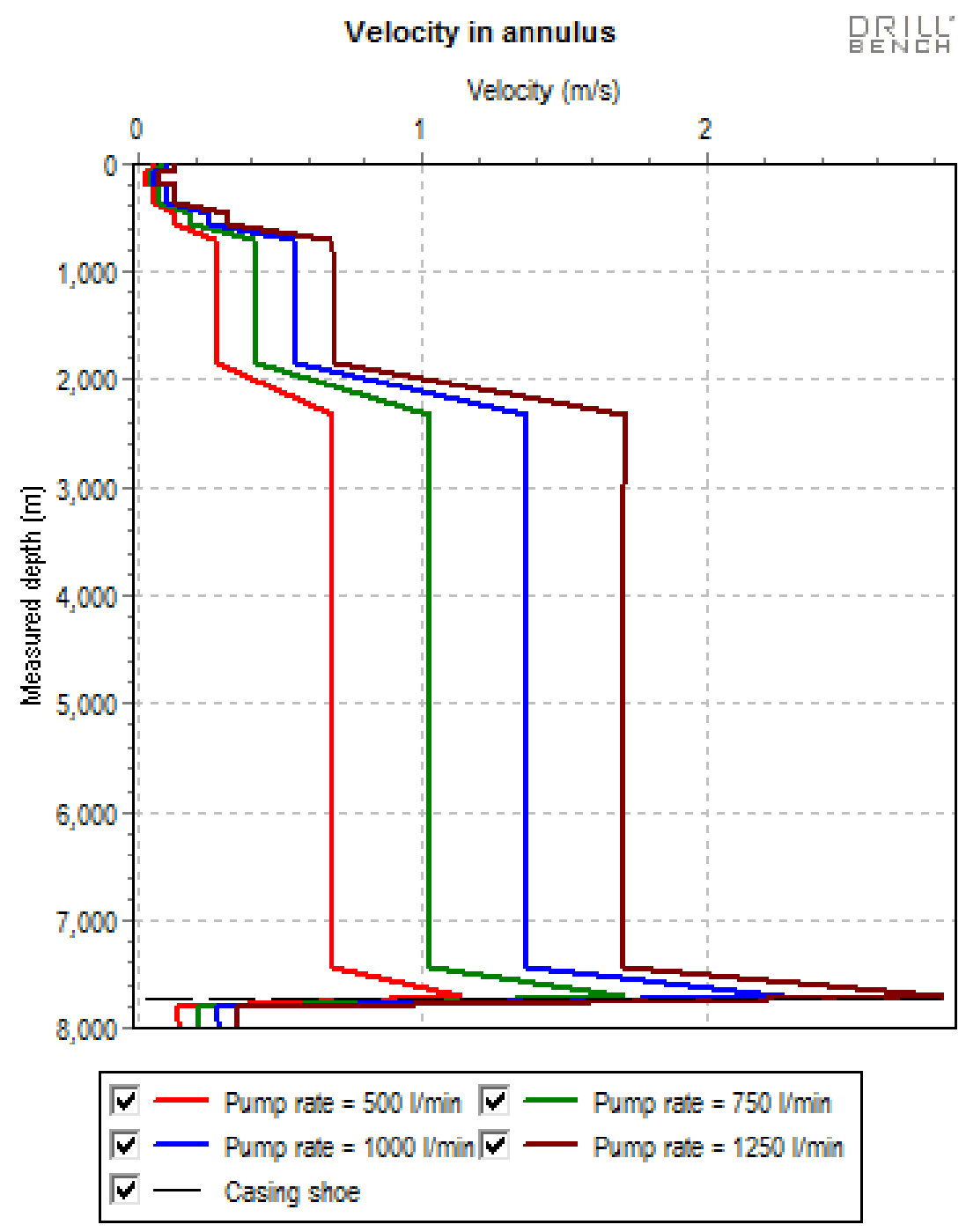

Figure 42: Annular velocity 


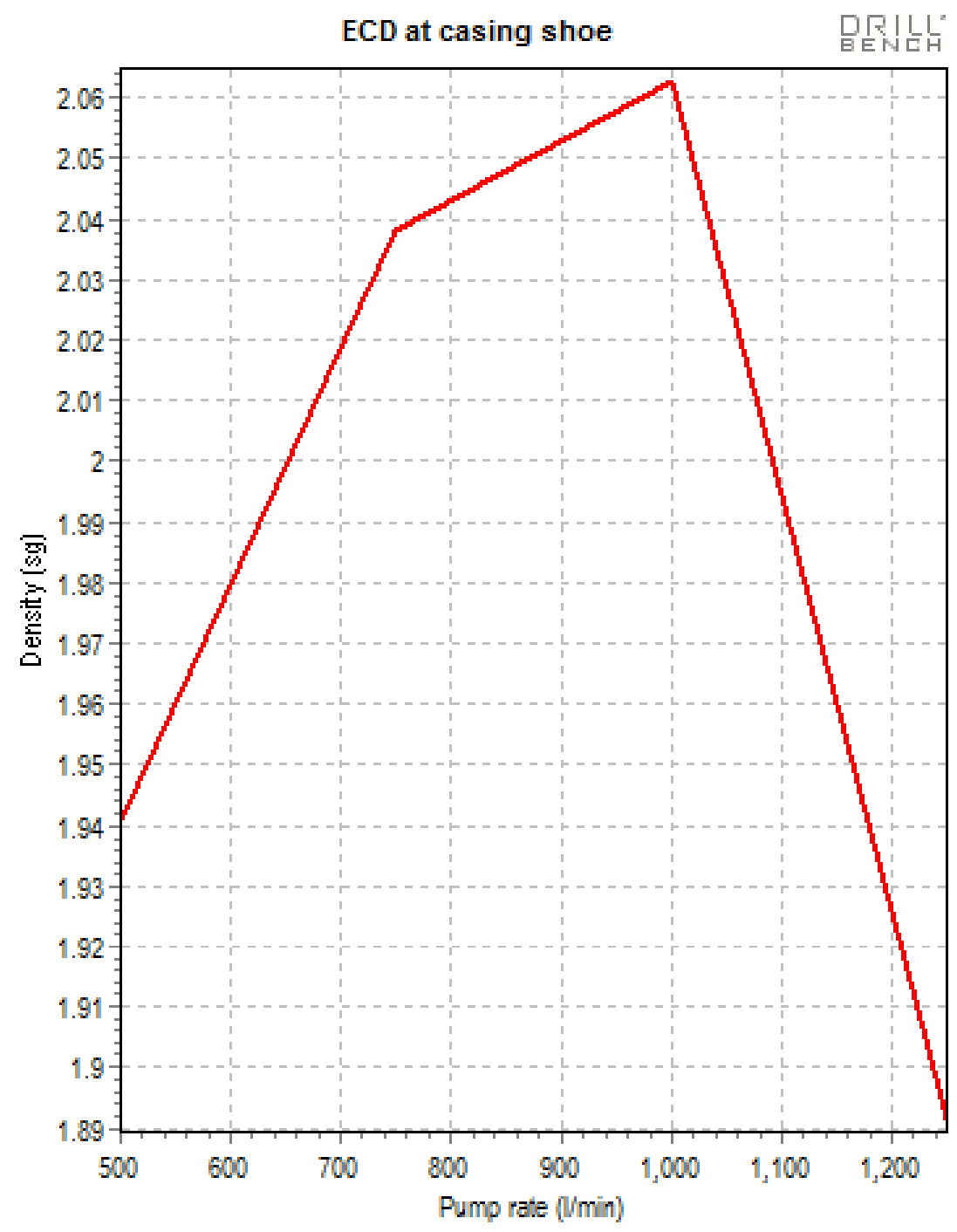

Figure 43: Equivalent circulation density at casing shoe 


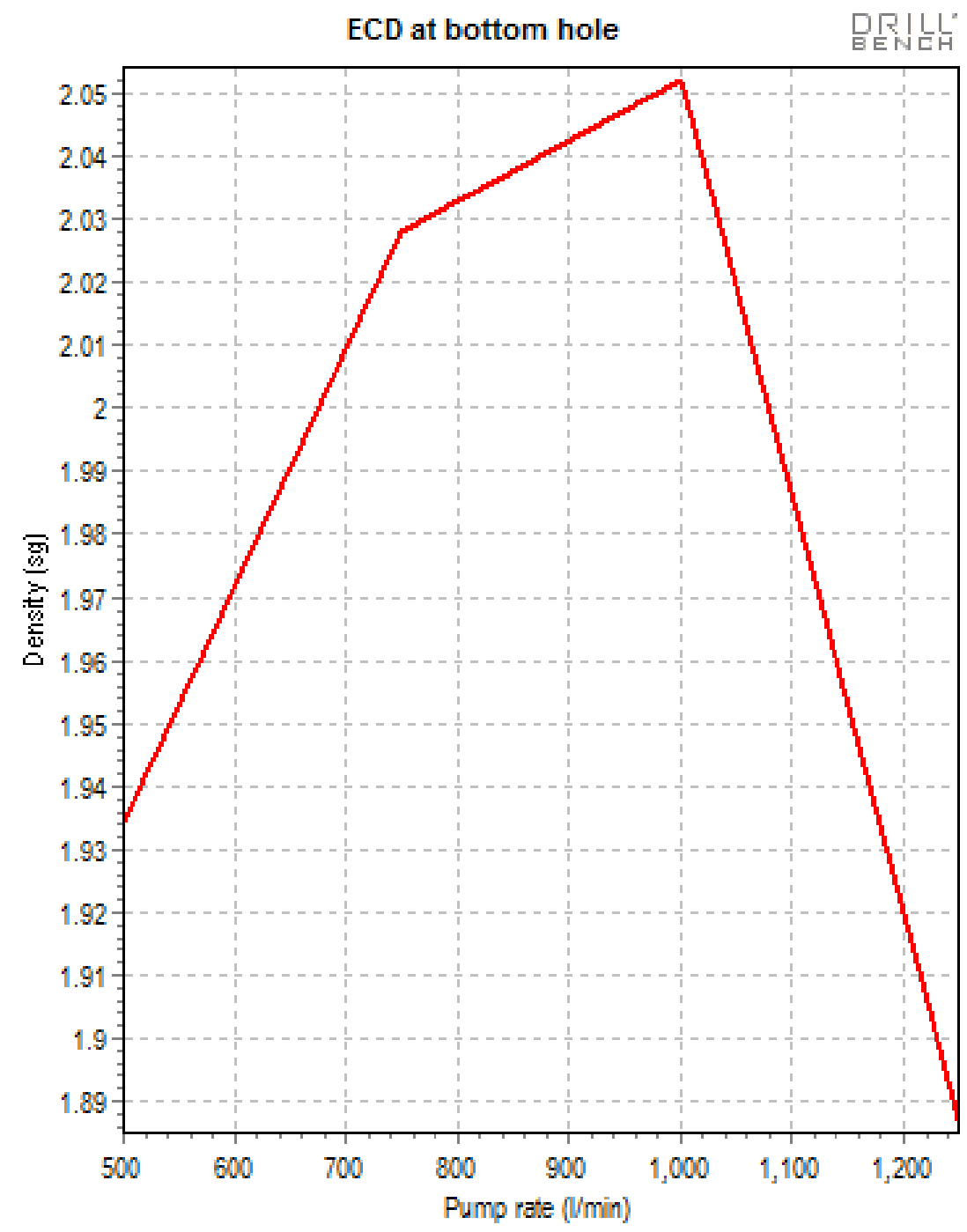

Figure 44: Equivalent circulation density at bottom hole 


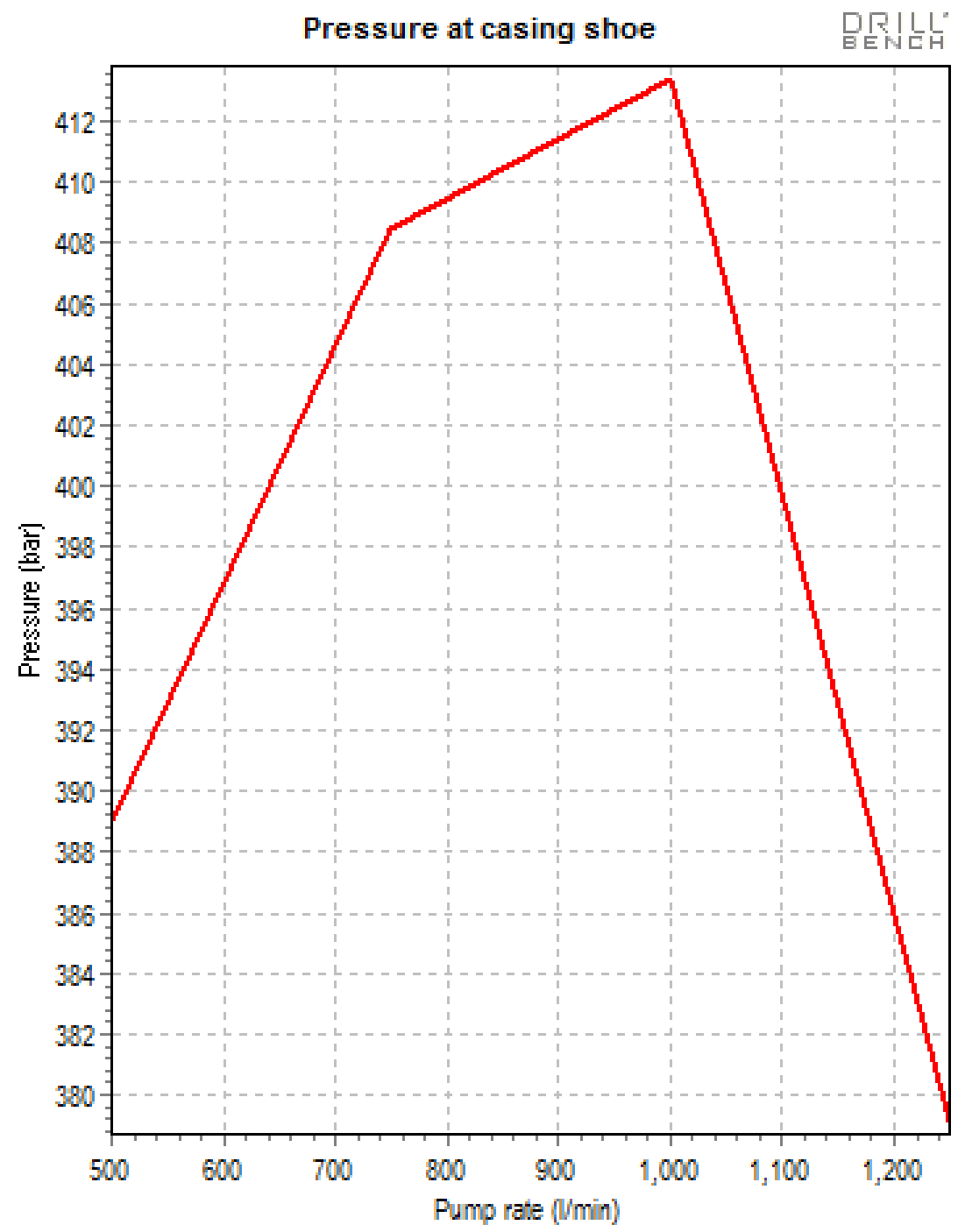

Figure 45: casing shoe pressure 


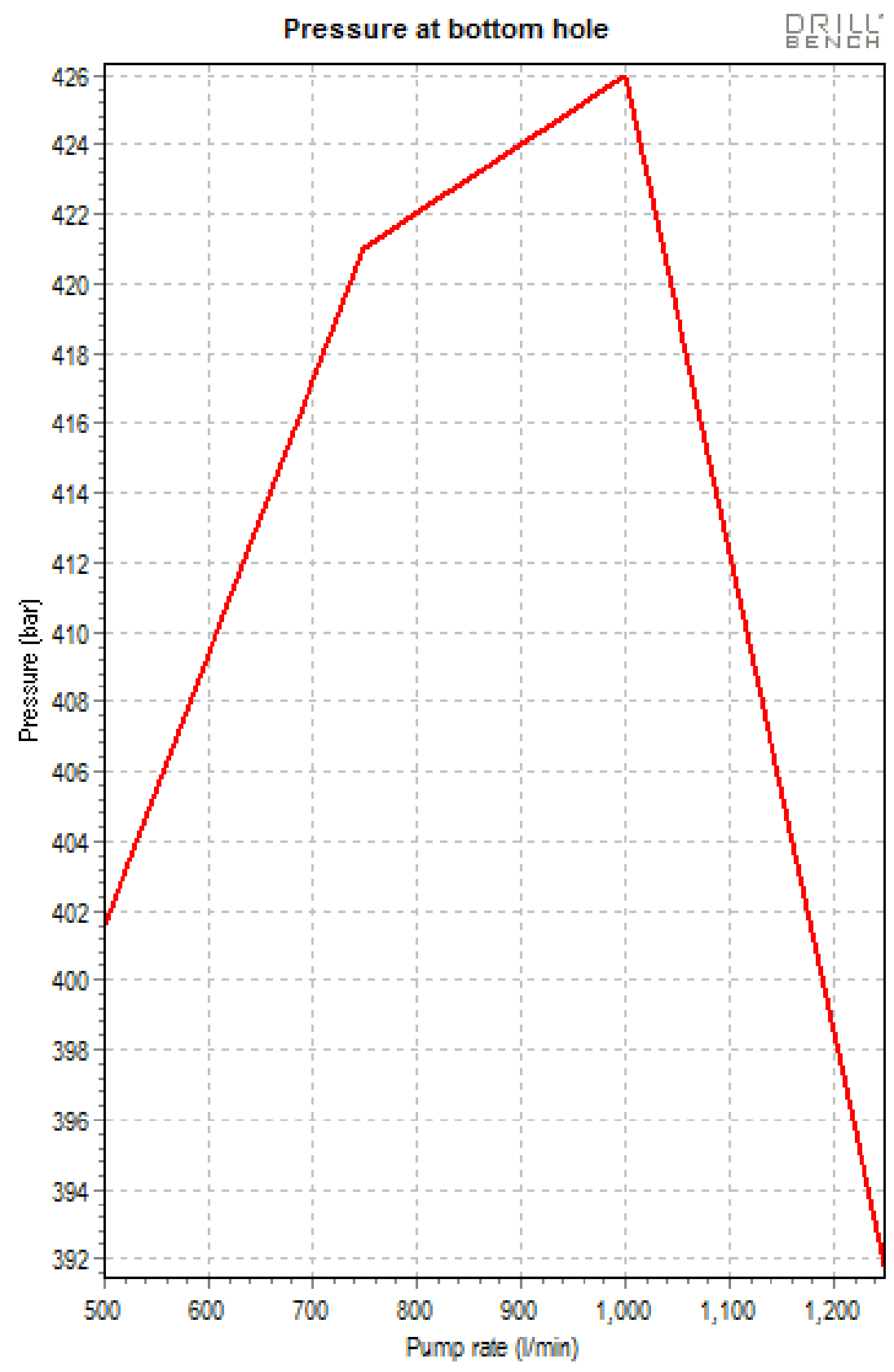

Figure 46: bottom hole pressure

Simulation with choke open 


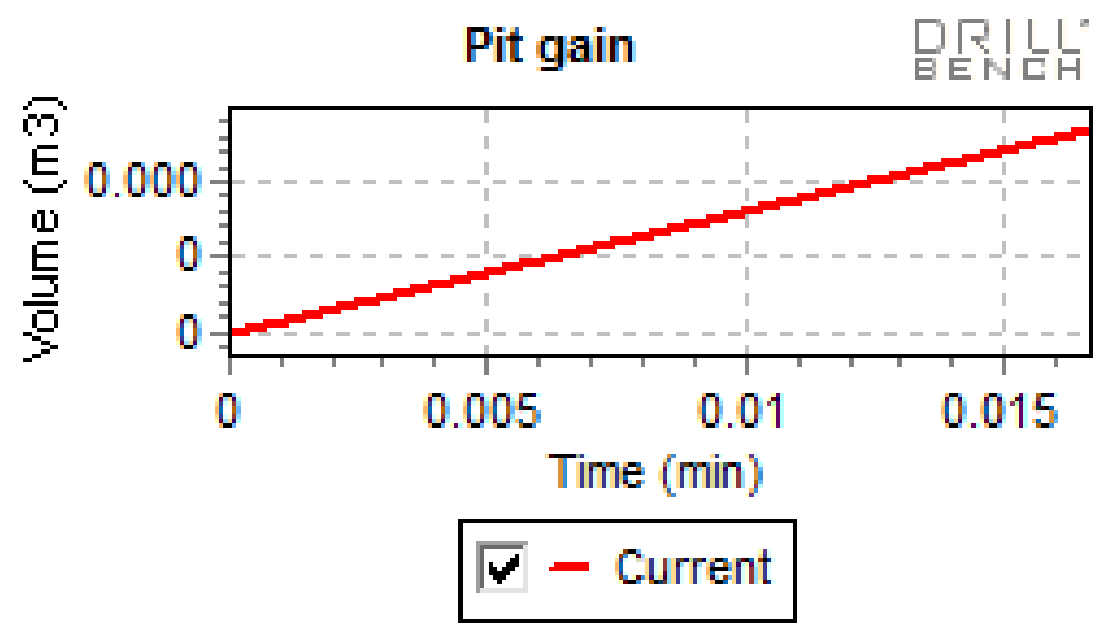

Figure 47: Pit gain

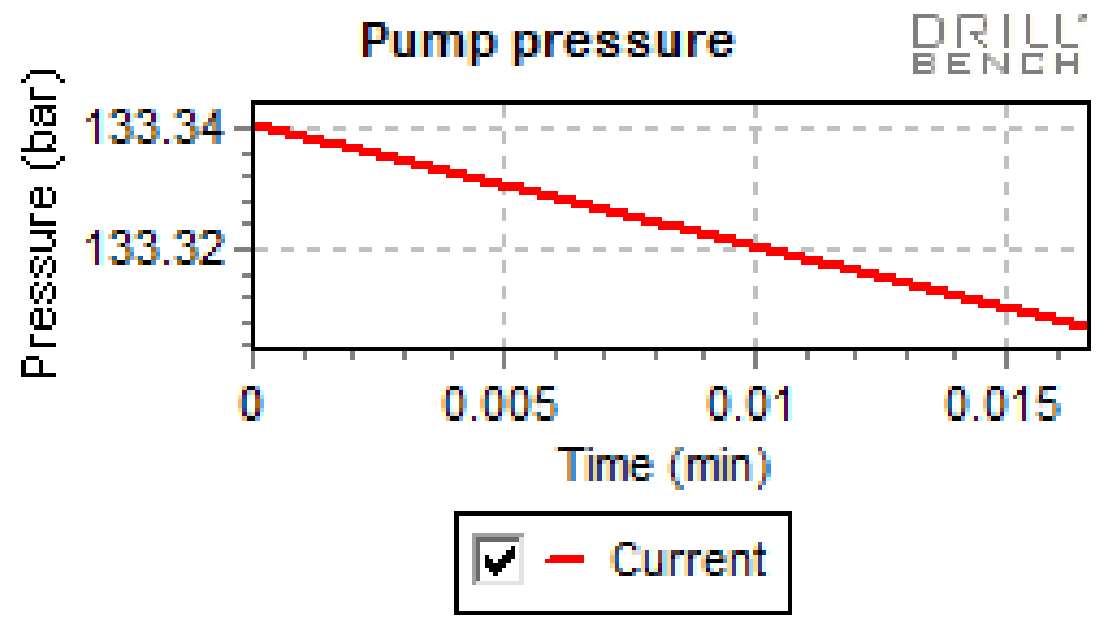

Figure 48: Pump pressure 


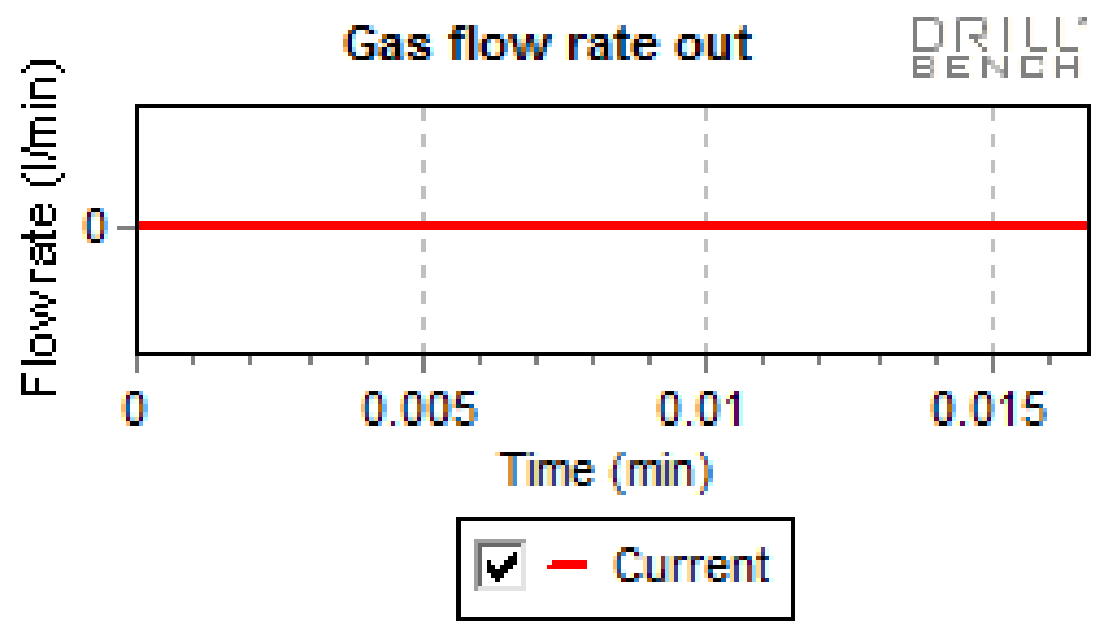

Figure 49: Gas flow rate

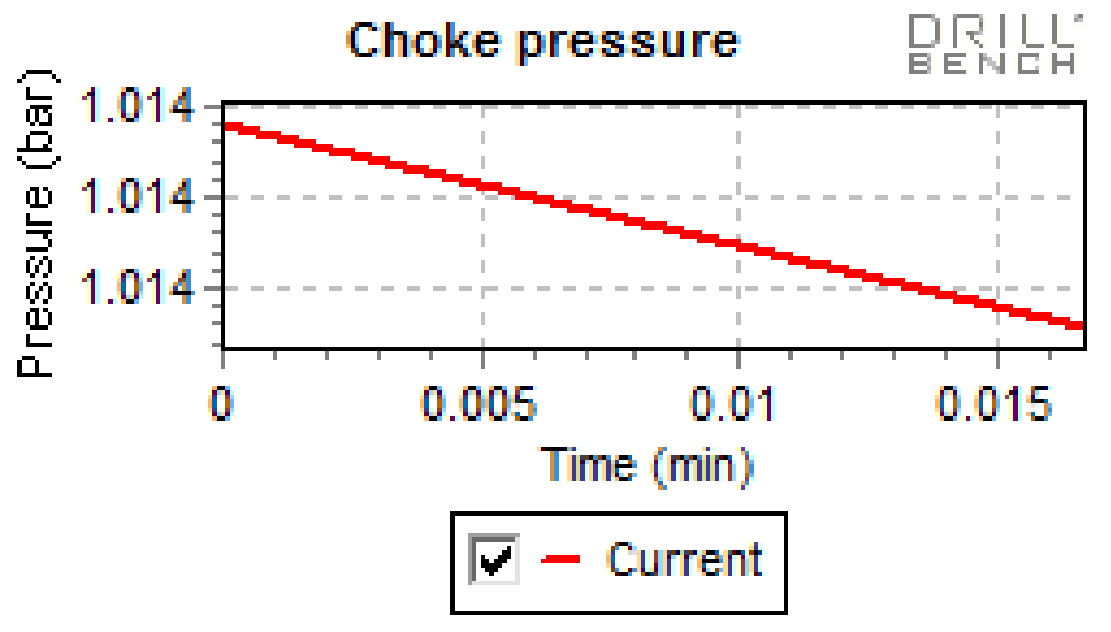

Figure 50: Choke pressure 


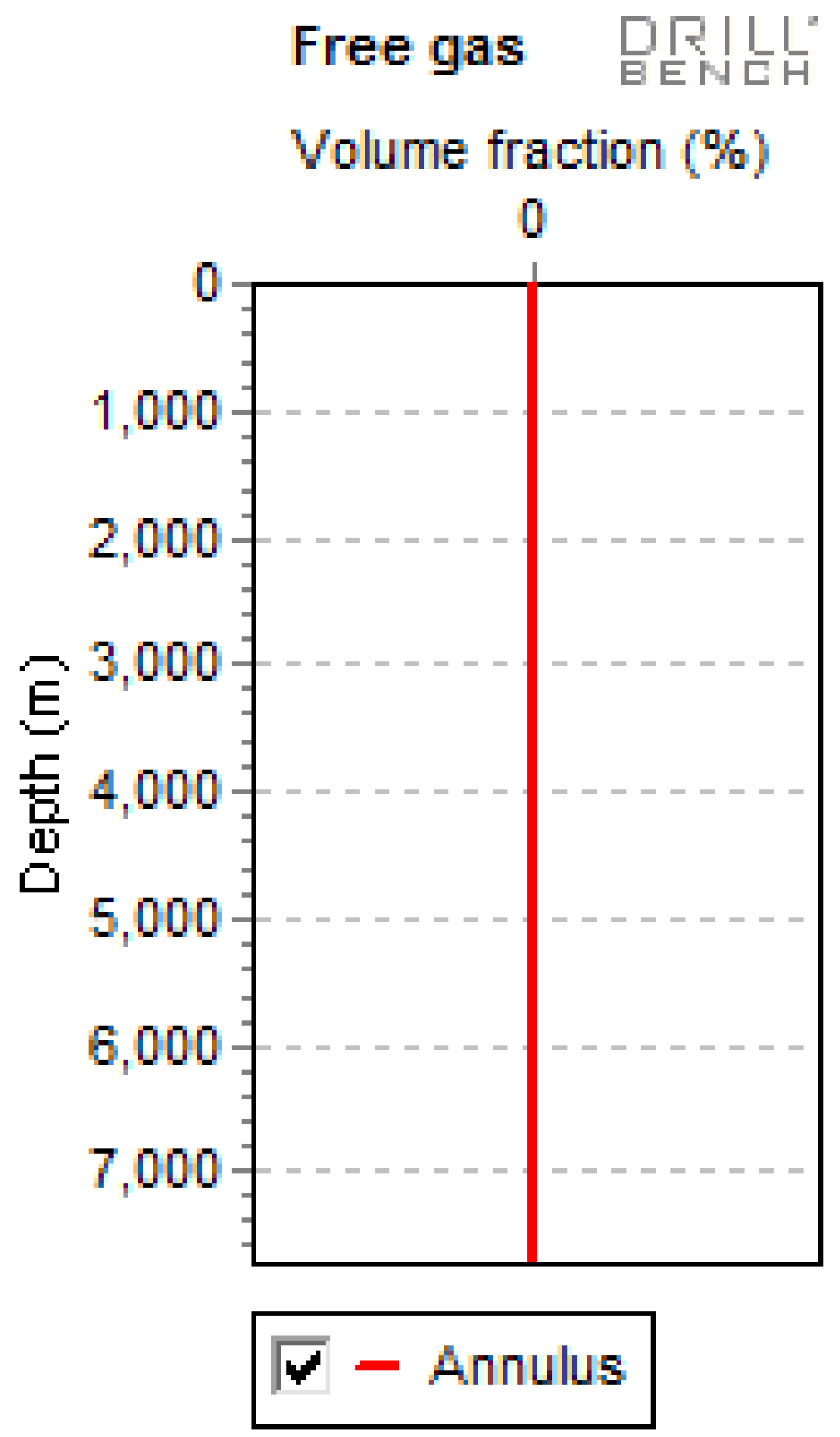

Figure 51: Free gas 


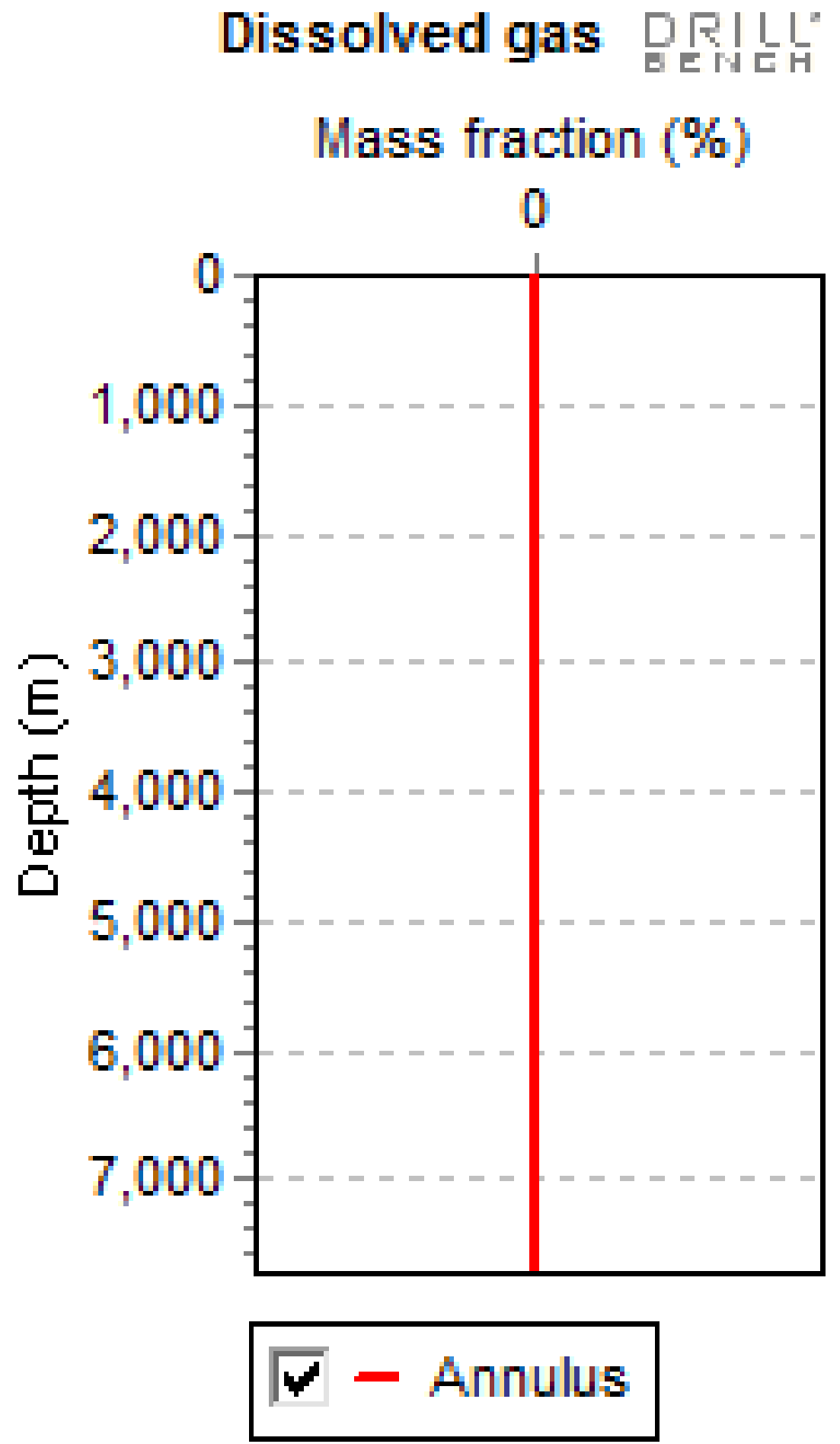


Figure 52: Dissolved gas 


\section{Pressure at casing shoe}

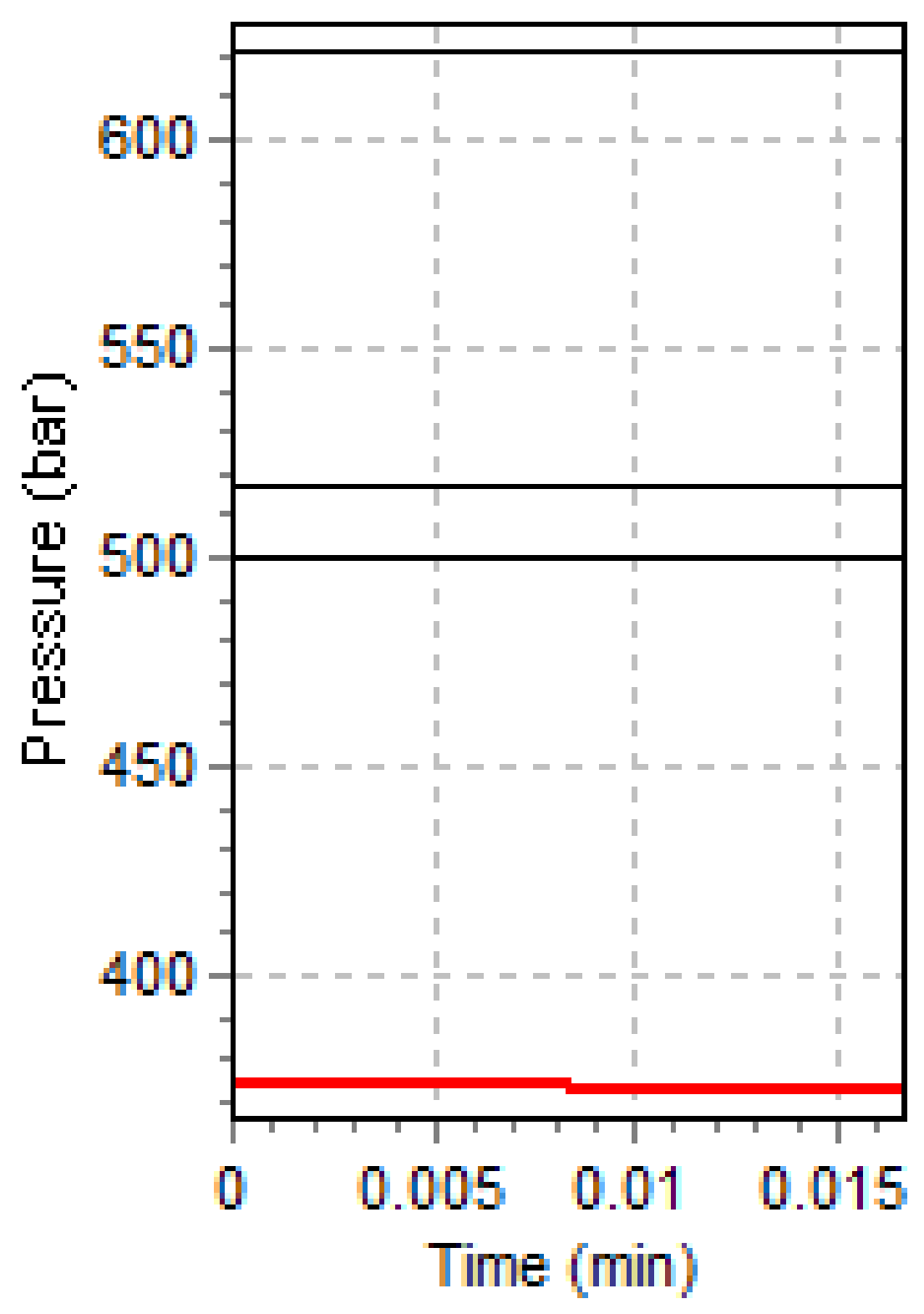

$$
\sqrt{\nwarrow}-\text { Annulus }
$$


Figure 53: Casing shoe pressure

Simulation with choke closed

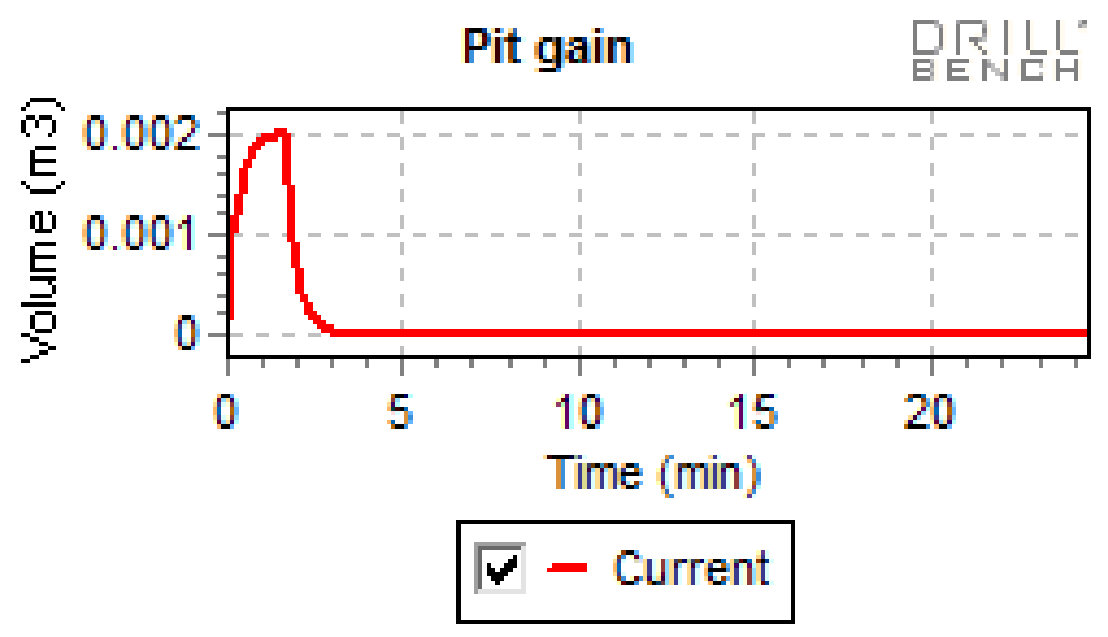

Figure 32: Pit gain

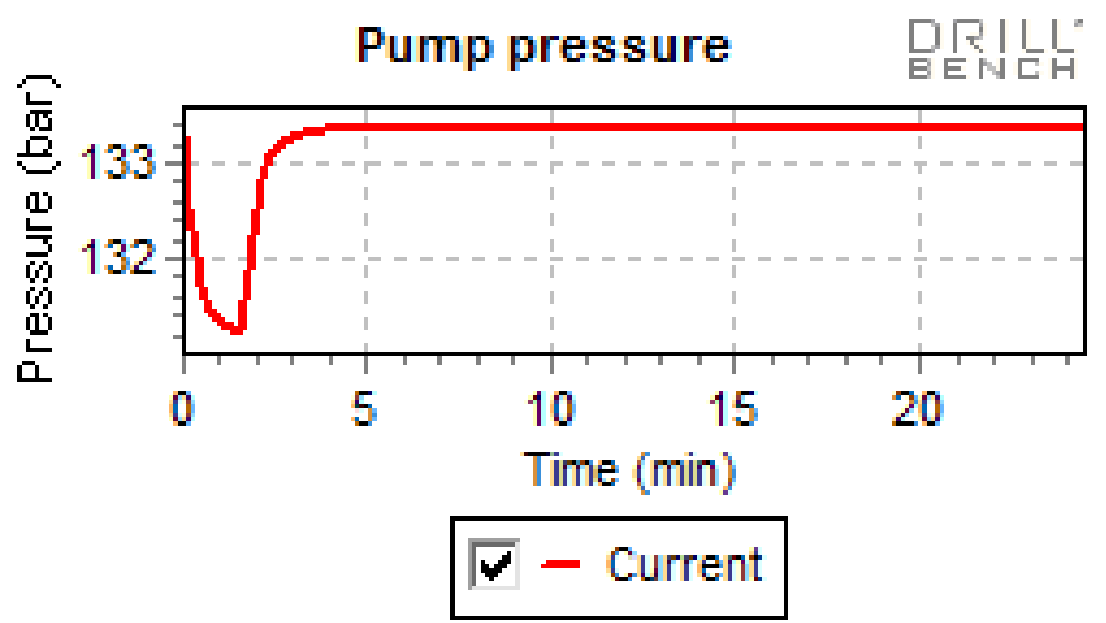

Figure 33: Pump pressure 


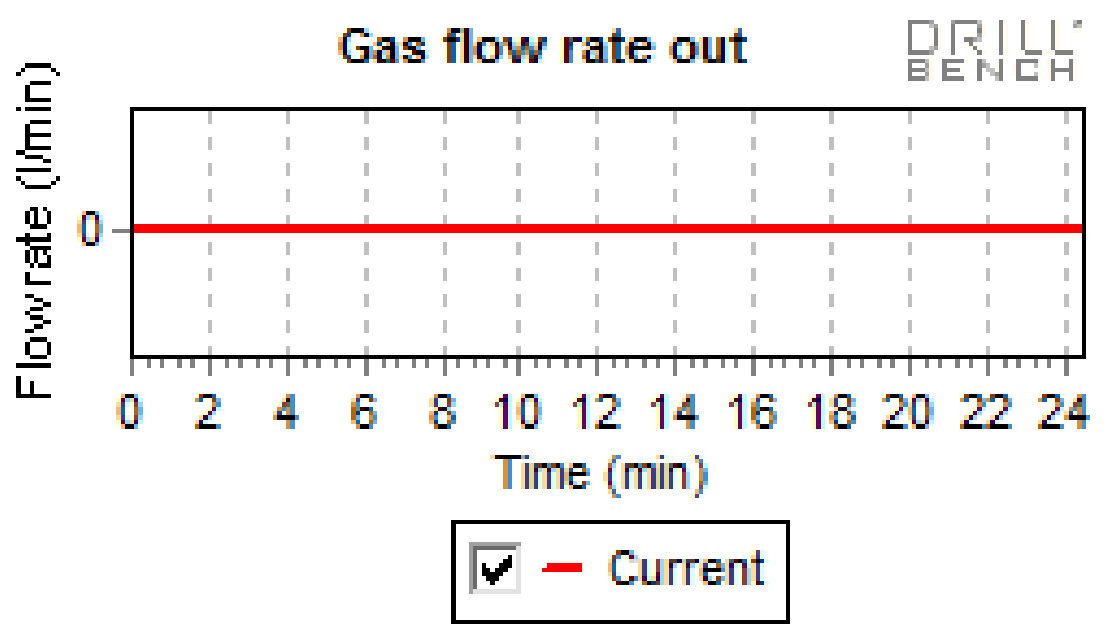

Figure 34: gas flow rate out

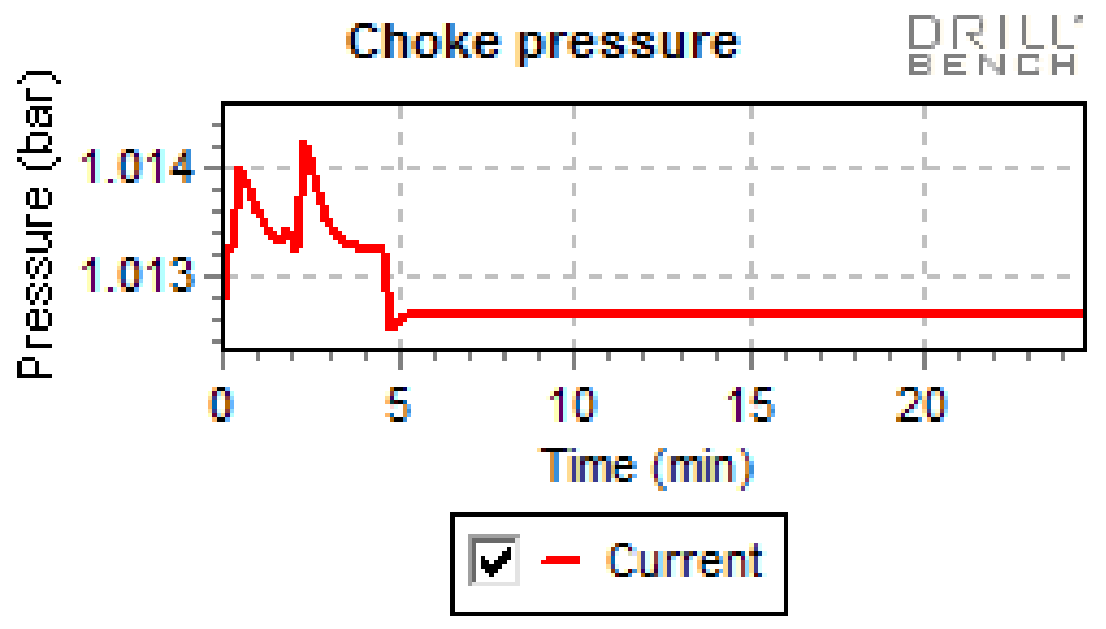

Figure 35: Choke pressure 


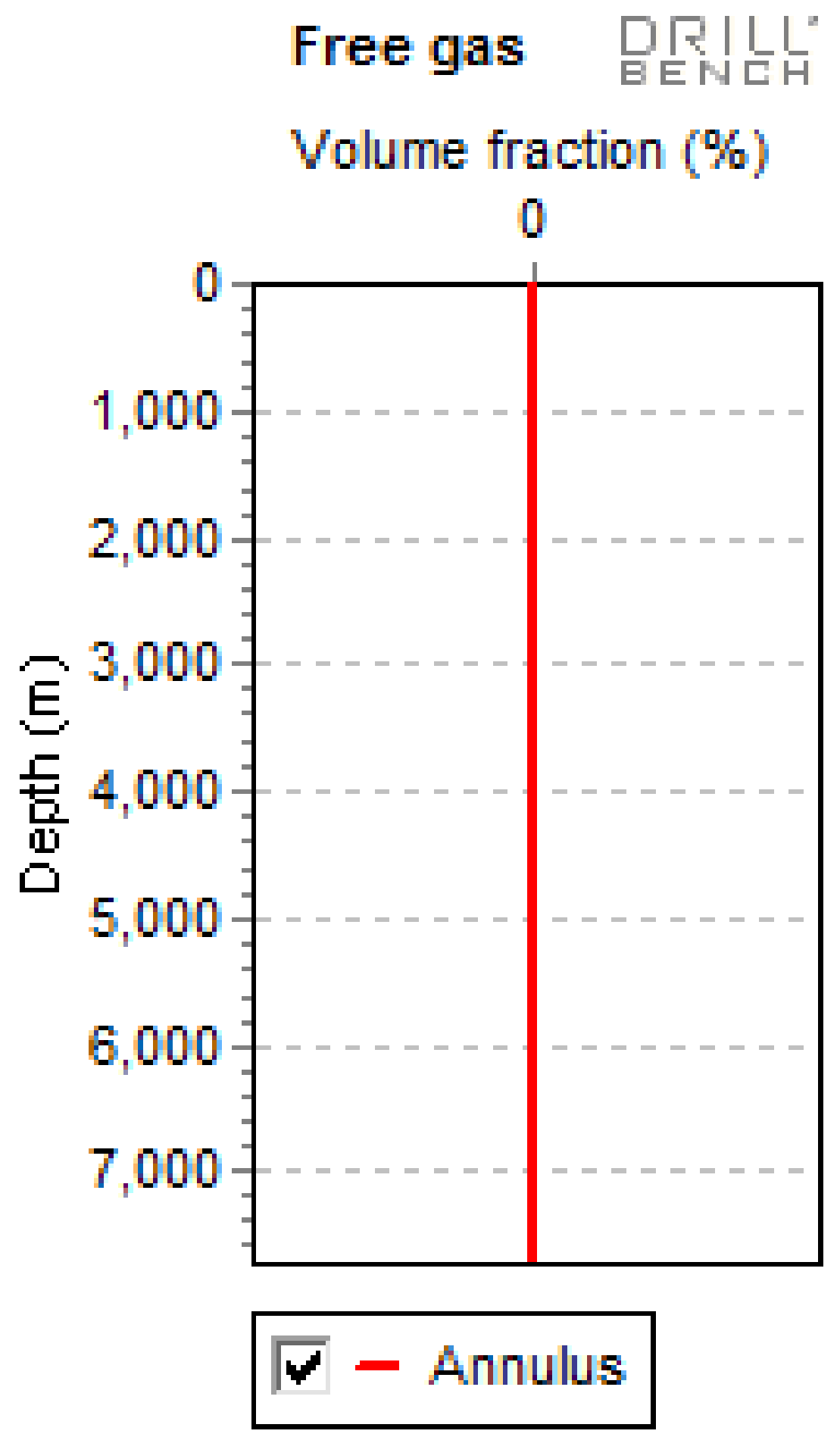

Figure 36: Free gas 


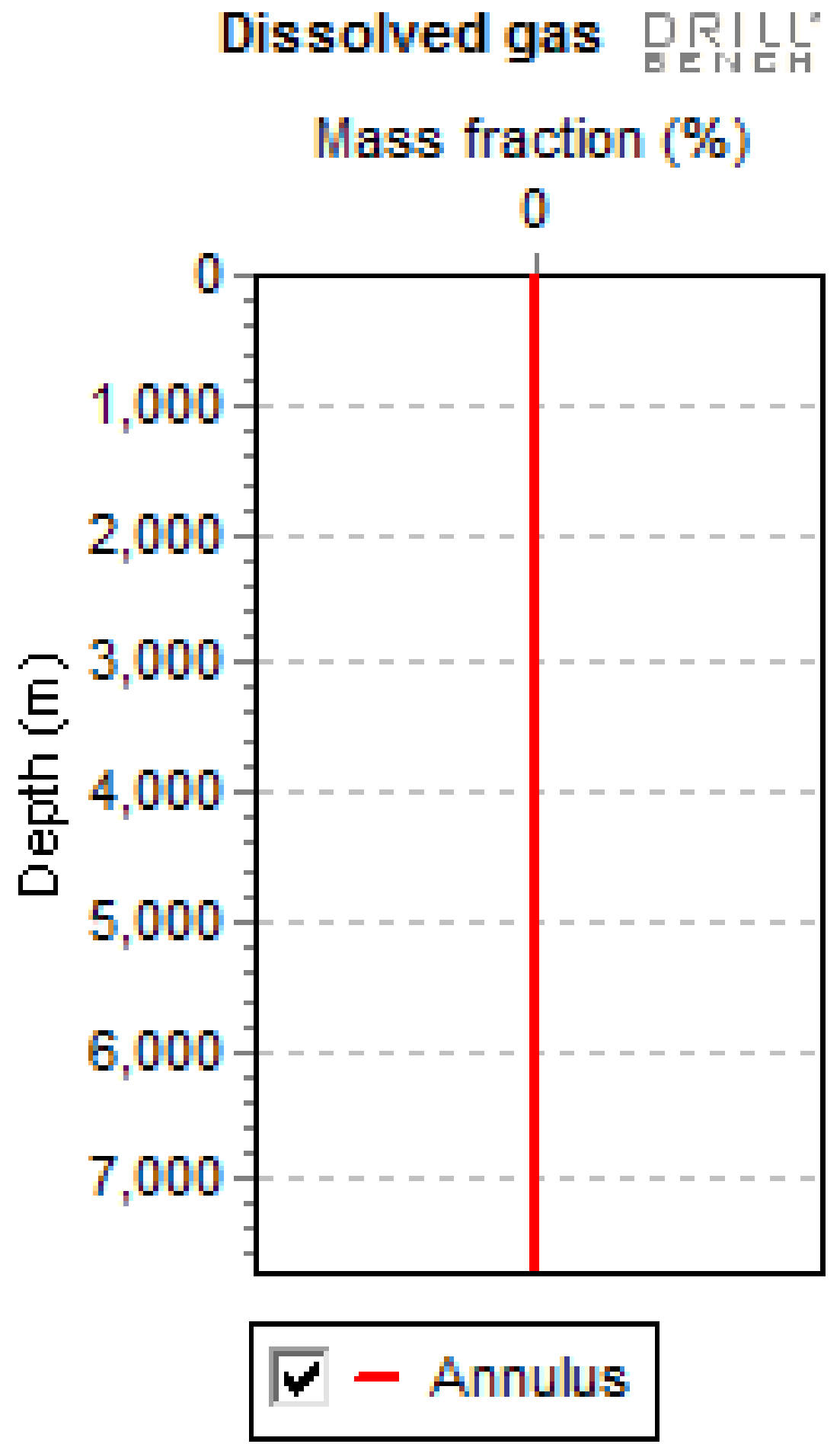


Figure 37: Dissolved gas

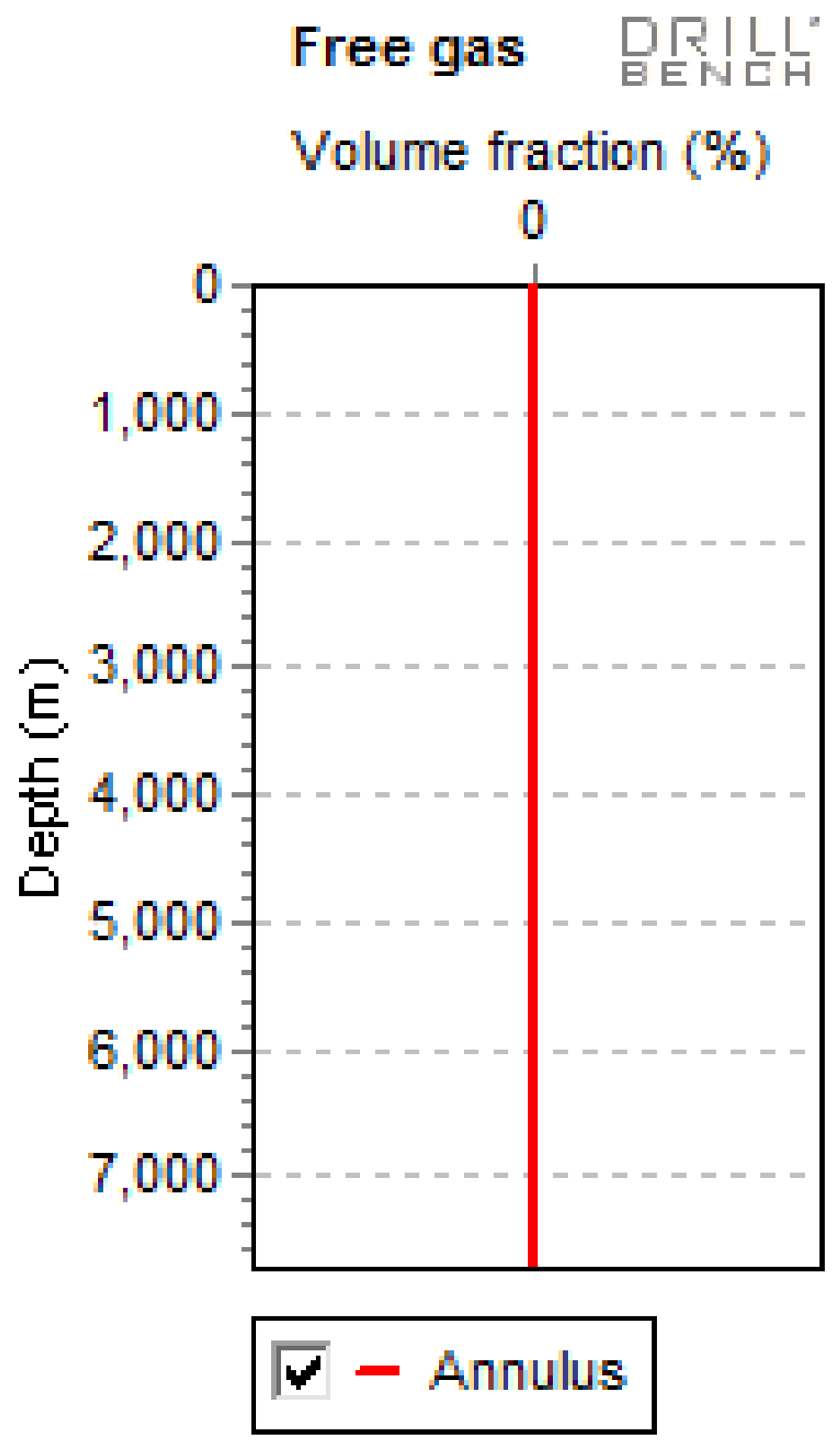


Figure 38: Pressure at casing shoe

\subsection{References}

1. Adekomaya, Olufemi \& Olafuyi, Olalekan. (2011). Experimental study of the effect of temperature on the flow behaviour of oil-based muds in Niger delta formation. Int. J. of Oil. 4. $322-334$. 10.1504/IJOGCT.2011.043715.

2. Drilling-mud.org, (2014). Plastic Viscosity (PV). [online] Available at: http://www.drillingmud.org/plastic-viscosity-pv/ [Accessed 13 Aug. 2014].

3. Glossary.oilfield.slb.com. (2014). The Oilfield Glossary - Schlumberger Oilfield Glossary . [online] Available at: https://www.glossary.oilfield.slb.com/ [Accessed 6 Jul. 2019].

4. Hemphill T, Campos W and Pilehvari A: "Yield-Power Law Model More Accurately Predicts Mud Rheology," Oil \& Gas Journal 91, no. 34 (August 23, 1993): 45-50.

5. Ogj.com, (1993). YIELD-POWER LAW MODEL MORE ACCURATELY PREDICTS MUD RHEOLOGY. [online] Available at: http://www.ogj.com/articles/print/volume-91/issue-34/in-thisissue/drilling/yieldpower-law-model-more-accurately-predicts-mud-rheology.html [Accessed 14 Aug. 2014].

6. Vincent A. Hackley, C. (2014). Guide to Rheological Nomenclature: Measurements in Ceramic Particulate Systems. [online] Ciks.cbt.nist.gov. Available at: http://ciks.cbt.nist.gov/ garbocz/SP946/node8.htm [Accessed 14 Aug. 2014]. 